\title{
LA NECESIDAD DE EMPODERAR EL ARBITRAJE COMO JURISDICCIÓN PRIVADA EN LOS PAÍSES IBEROAMERICANOS
}

\section{THE NEED TO EMPOWER ARBITRATION AS A PRIVATE JURISDICTION IN THE IBERO-AMERICAN COUNTRIES}

\author{
Dr. Dr. Dr. H.C. Gino Ríos Patio \\ Director del Instituto de Investigación Jurídica \\ Universidad de San Martín de Porres \\ griosp@usmp.pe \\ www.ginoriospatio.com \\ Perú, Lima
}

\section{SUMARIO}

- Introducción

- El conflicto y los medios alternativos para su resolución

- Evolución, naturaleza y bondades del arbitraje

- Ética y arbitraje

- Análisis constitucional del arbitraje

- Elogio del arbitraje

- Conclusiones

- Fuentes de información

\section{RESUMEN}

El autor expone la crítica situación de la jurisdicción estatal frente a la resolución de los conflictos intersubjetivos y la desconfianza e inseguridad que tiene la ciudadanía respecto del funcionamiento de dicha jurisdicción; exhibe en contra posición los fundamentos y el mérito del arbitraje como medio heterónomo eficaz de solución de conflictos; y analiza, a la luz de las constituciones políticas latinoamericanas, algunos de los problemas más relevantes que frenan su desarrollo, entre los cuales destaca la falta de reconocimiento como jurisdicción y la ausencia de ejecutabilidad autónoma y coercibilidad de las medidas cautelares y del laudo. Asimismo, explica y pondera los fundamentos del arbitraje, para concluir en una apología de dicha institución y reafirmar la inaplazable necesidad de su empoderamiento como jurisdicción privada frente a la crisis de seguridad jurídica, corrupción y dilación de la jurisdicción ordinaria.

\begin{abstract}
The author exposes the critical situation of the state jurisdiction against the resolution of intersubjective conflicts and the distrust and insecurity that citizens have regarding the operation of said jurisdiction; it exhibits against the position the fundamentals and the merit of arbitration as an effective heteronomous means of conflict resolution; and analyzes, in the light of the Latin American political constitutions, some of the most relevant problems that hinder its development, among which the lack of recognition as a jurisdiction and the absence of autonomous enforceability and coercibility of the precautionary measures and of the award stand out. It also explains and weighs the foundations of arbitration, to conclude in an apology of said institution and reaffirm the unavoidable need for its empowerment as a private jurisdiction in the face of the crisis of legal security, corruption and delay of ordinary jurisdiction.
\end{abstract}

\section{PALABRAS CLAVES}

Medio heterónomo de resolución de conflictos; arbitraje; tutela jurisdiccional; jurisdicción privada. 


\section{KEYWORDS}

Heteronomous means of conflict resolution; arbitration; jurisdictional protection; private jurisdiction.

\section{INTRODUCCIÓN}

El autor parte de un dato objetivo que está presente en la realidad del Perú y de los países iberoamericanos, en similares niveles y proporciones, cual es, el ineficaz funcionamiento de la justicia estatal, debido a diversos motivos, como son, la excesiva dilación de los procesos; los extensos plazos; los exagerados rigorismos; la sobre carga procesal; la ausencia de vocación de justicia; la falta del concepto de servicio público de los administradores de justicia; la incompetencia funcional de los operadores estatales del sector; la falta de independencia e imparcialidad; la excesiva aprensión frente a la presión mediática; la corrupción generalizada, entre otros; cuya consecuencia estriba en que el servicio de justicia estatal no cumple con el fin para el cual ha sido creado, esto es, otorgar tutela jurisdiccional efectiva, proteger derechos fundamentales, intereses y bienes jurídicos, discernir justicia racionalmente de manera célere, predictiva y segura jurídicamente, así como contribuir desde ese espacio de discernimiento de justicia a la construcción de la paz social.

El problema entonces es el deficiente funcionamiento y la incorrecta operatividad de la organización de justicia estatal.

En las constituciones políticas de los estados liberales, el poder emana del pueblo y el poder de administrar justicia también. Ocurre, sin embargo, que la justicia es administrada directamente por jueces profesionales que no son elegidos democrática ni directamente por el mismo pueblo sino por organismos que en la formalidad constitucional se les denomina autónomos, cuyos miembros han resultado elegidos -en el caso del Perú- de manera curiosa, para utilizar un eufemismo indulgente, lo que los lleva a cumplir una actividad más bien oligárquica.

En otros sistemas de administración de justicia, el pueblo actúa a través de la institución del jurado, conformado por ciudadanos no abogados, elegidos por sorteo para la resolución de un conflicto intersubjetivo. Cuando la conformación del órgano de justicia es mixta, aunque con clara mayoría de ciudadanos no abogados, estamos frente al sistema denominado escabinado. Estos dos últimos sistemas no son frecuentes en los países iberoamericanos o son desconocidos, razón por la cual el presente artículo se ocupa exclusivamente, como modelo de referencia, de la justicia estatal, que es el modelo con más defectos que se conoce, siendo asimismo el que no es ejercido directamente por el titular del poder.

Frente a esta problemática social y política, el objetivo central del artículo es el de mostrar el descrédito del modelo de justicia estatal ante la ciudadanía y confrontarlo con un medio alternativo de resolución de conflictos, como es el arbitraje, a fin de patentizar la necesidad de su empoderamiento como jurisdicción para asegurar su desarrollo, como una importante manera de resolver los conflictos que de otra manera permanecen intactos al no encontrar solución adecuada en la administración de justicia estatal o, en el mejor de los casos, la obtienen después de un largo tiempo y a un costo muy oneroso, lo cual fomenta mayor corrupción, ocasionando la sedimentación de conflictos en la sociedad.

Evidentemente, como cultor de la libertad e iniciativas privadas, el autor desarrolla un panegírico sobre el arbitraje, luego de pronunciarse sobre algunos problemas colaterales derivados de la coexistencia de ambos sistemas de justicia, el estatal y el arbitral, con la finalidad manifiesta de contribuir a su legitimidad y aceptación social, en aras de su desarrollo; arribando a la conclusión principal de que la justicia arbitral merece, por su origen, naturaleza, características y operatividad, estar más extendida en esta región del planeta, lo que conllevaría el redimensionamiento de la justicia estatal $\mathrm{y}$, acaso, la corrección de su operatividad, aunque el autor no cree que esto último se pueda obtener, por cuanto el mal funcionamiento depende en mayor medida del diseño estructural del sistema orientado por el poder de facto no proveniente del pueblo.

Así, el estudio y análisis del problema se inicia con el conflicto y los medios de resolución para recordar que es una entidad natural en el hombre, pero superable, de lo contrario la humanidad ya se hubiera extinguido; 
en los países iberoamericanos

The need to empower arbitration as a private jurisdiction in

the ibero-american countries

continúa con la evolución del arbitraje para conocer su naturaleza; prosigue con la valía y preeminencia del arbitraje merced a sus bondades estructurales; la presencia de la ética en el arbitraje como elemento insustituible; un análisis constitucional del arbitraje; un ensayo de fundamentación de derecho público para una institución privada, como es el arbitraje; los problemas actuales del arbitraje, entre los que se cuenta su relación con la justicia estatal; y un elogio de la institución arbitral, para finalmente arribar a las conclusiones, que el autor considera oportunas para presentar la expansión del arbitraje como una urgente y seria alternativa frente al descrédito de la justicia pública.

\section{EL CONFLICTO Y LOS MEDIOS ALTERNATIVOS PARA SU RESOLUCIÓN}

\section{El conflicto}

El ser humano es falible y variable. Sus intereses cambian en función de las circunstancias personales y la interacción social que entabla con sus semejantes. De ahí que la dinámica social contenga las causas del conflicto a partir de la omni presencia de incompatibilidades de intereses y objetivos. Indudablemente, el conflicto es inherente al ser humano.

Es fácil advertir, de otro lado, que el conflicto genera tensión y problemas para las partes involucradas y la sociedad en general, más aún si no se soluciona o si se soluciona mal, dando lugar a un pleito que tenga que ser dirimido por un tercero, que usualmente suele ser el Estado $\mathrm{y}$, eventualmente, un árbitro.

El significado etimológico de la palabra conflicto es el de choque y confrontación, lo cual evidentemente trae como consecuencia una aflicción para una o más partes, sea porque es vencida o porque, aun siendo vencedora, el costo de la victoria le resulta muy oneroso.

El conflicto, por su naturaleza adversarial, se percibe como una situación disfuncional, por cuanto las partes recíprocamente se ven como obstáculos para la consecución de sus respectivos intereses. Sin embargo, es posible que la aparente pugna no sea por el acceso a determinados recursos, sino apenas por una percepción indebida del acceso a los mismos. En ese sentido, resulta más constructivo entender el conflicto como un proceso pleno de interacciones que emergen, se desarrollan, se transforman y llegan a desaparecer. Esta visión implica necesariamente una conciencia y un compromiso con la búsqueda de soluciones y la edificación del cambio, lo que anticipamos solo se puede lograr en los cauces flexibles de un proceso liderado por las partes y dirigido por un árbitro, no por el ceñido corsé mental de un juez togado, que permanece atado a una lógica procedimental anquilosada. De lo contrario, al no existir deber y responsabilidad para resolver el conflicto, como no la tiene el funcionario público, permanece y genera una espiral de problemas que constituyen una traba al desarrollo personal y social.

Esta naturaleza antagónica y litigiosa de la diferencia conflictual entre dos o más personas, hace que deba manejarse positivamente, buscando oportunidades de solución a fin de contribuir a hacer un proceso incesante de arquitectura de las relaciones sociales para motivar los cambios necesarios de manera adecuada en términos de costo y oportunidad, lo que no se puede obtener en un proceso judicial porque las partes se consideran recíprocamente como némesis una de la otra, destinadas a vengarse mutuamente en juicio.

Más aún, en vista que las diferencias conflictuales surgen recíprocamente entre las partes intervinientes, es menester concienciar a las personas sobre la conveniencia de la cooperación y no del antagonismo para zanjar la contienda, de forma tal que ambos ganen algo. Así, resulta necesario cambiar la impresión que tenemos del conflicto como algo perjudicial y nocivo, para entenderlo como una ocasión propicia para construir nuevas oportunidades que resuelvan las diferencias. De paso, es preciso decir que también existe la necesidad de cambiar el concepto que tenemos del Derecho como únicamente un instrumento de prohibiciones y coerción, para comenzar a concebirlo como una herramienta de facilitación y concreción de las libertades individuales, precisamente para evitar conflictos o solucionarlos. Esta apertura se viabiliza por medio del arbitraje, que actúa como un mecanismo decantado de búsqueda de soluciones a un conflicto.

Frente a un conflicto, las partes o el tercero a cargo de su resolución, sea conciliador, mediador o árbitro, deben en primer lugar 
determinarlo, precisando los puntos en que consiste y las razones de las posiciones encontradas; y luego deben enfocar las posibles causas y las expectativas que las partes tienen en su resolución; pero en todo momento debe mantenerse el interés de las partes en la resolución, a fin de estimular la cooperación mutua para que se alcance una resolución recíprocamente beneficiosa. Esta omnipresencia del interés resolutorio no existe en la justicia estatal, debido a la demora del proceso y las vicisitudes que se presentan en su transcurso.

En efecto, la justicia estatal, lamentablemente, genera lo contrario. Las partes acuden a ella como contrincantes y mantienen esa posición inalterablemente, porque quieren derrotar al adversario, cueste lo que cueste, por lo que se internan en un laberinto kafkiano con tal de salir gananciosos, terminando por el contrario extraviados a un alto costo. Es, más bien, una oportunidad perdida, desde que se ve como una instancia obligatoria y perniciosa, aunque el juez finalmente le conceda la razón. El análisis costo beneficio no es, precisamente, una ventaja diferencial de la justicia estatal, debido al excesivo tiempo que demoran los procesos judiciales y la no predictibilidad de las decisiones jurisdiccionales por motivos de corrupción o incompetencia funcional, lo cual afecta sensiblemente la seguridad jurídica a la que todos aspiran.

\section{Los medios alternativos de resolución de conflictos}

Los medios alternativos son aquellos mecanismos no formales a cargo de un tercero, en los que se busca la resolución de los conflictos con una óptica distinta al procedimiento de resolución formal a cargo de la función jurisdiccional del Estado, en la que prevalece una perspectiva de humanización y solidaridad para superar las diferencias.

Tienen antigua data, mayor que la justicia estatal, pues siempre correspondió a la iniciativa y autonomía privada dirimir sus diferencias directamente, pues se trataba de los directamente involucrados. Empero, a partir del siglo XIII, como señala Anitúa, G. (2015) con el advenimiento del Estado monárquico absolutista, éste monopoliza la potestad de administrar justicia y somete a las partes del conflicto a una posición en la que solamente le queda cumplir con lo que decida el Estado, para lo cual crea personal burocrático dependiente de su poder, como fueron el procurador del Rey en materia penal, los jueces y alguaciles, así como, más tarde, la burocracia judicial, todos los que, naturalmente, actuaban conforme a los dictados del poder, debido a un extraño concepto de lealtad originado en el pago de sus servicios.

Es válido reflexionar si acaso la moderna y liberal separación de las funciones estatales haya conllevado, en el caso de la función de administrar justicia, dicho descrédito a contrapelo de la mentada independencia judicial.

Estas formas alternativas de resolución de conflictos son la negociación, la mediación, la conciliación y el arbitraje.

En la negociación, las mismas partes involucradas llegan directamente a un acuerdo a través de la comunicación, el respeto y la consideración, facilitándose el intercambio para satisfacer objetivos. Corresponde, en realidad, a la forma más prístina, directa y racional de resolver los conflictos intersubjetivos.

En la mediación, en cambio, un tercero imparcial coopera con las partes para que ellas encuentren una solución al conflicto, actuando como un facilitador durante todo el proceso. Aquí se pone en evidencia la solidaridad social de la comunidad a través de un tercero, lo que constituye una forma democrática de deliberación y resolución del conflicto.

En la conciliación, también interviene un tercero imparcial, el cual actúa con el consentimiento de las partes o por mandato de la ley, para ayudar a los actores a llegar a un acuerdo que los beneficie. Este medio complementa el sistema de justicia, sea en la misma instancia judicial o fuera de ella. En el Perú, la Ley $\mathrm{N}^{\circ} 26872$ obliga a seguir este medio como condición sine qua non o requisito de admisibilidad de una futura demanda en determinadas materias civiles, tales como los que versen sobre pretensiones determinadas o determinables de derechos disponibles de las partes; alimentos, régimen de visitas, tenencia, liquidación de sociedad de gananciales y otras que se deriven de la relación familiar, lo cual ha originado que el potencial demandante invita a conciliar a su antagonista como una mera formalidad vacía de contenido, esto es, 
en los países iberoamericanos

The need to empower arbitration as a private jurisdiction in

the ibero-american countries

sin tener realmente la intención de llegar a un acuerdo, sino únicamente de cumplir con el requisito legal.

Cabe preguntarse por qué el Estado intervino solamente en la conciliación, y no así en la mediación, para contaminar su autenticidad deliberativa y resolutiva. Por lo menos en el Perú, la respuesta tiene que ver con la introducción y promoción de la conciliación desde el mismo Estado, así como con su inefectividad por motivos culturales que apuntan a iniciar y desenvolver disputas debido a una idiosincrasia litigiosa y de falta de comunicación deliberativa entre los ciudadanos, por lo que se decidió intervenir desde el Estado para hacerla requisito obligatorio para iniciar procesos judiciales en determinadas materias, con lo cual se esterilizó la conciliación y terminó por hacerla fracasar.

Sería interesante al respecto contar con una data sobre la cantidad de invitaciones a conciliar como requisito previo a la demanda judicial y la cantidad de conciliaciones logradas pre judicialmente. Asimismo, con una data de conciliaciones judiciales intra proceso. Lastimosamente no existen en el Perú. Pero el autor está seguro que la cantidad de conciliaciones extra judiciales y judiciales logradas, es insignificante, si es que hay alguna. Esta circunstancia revelaría la ausencia de razonabilidad entre las partes inmersas en el conflicto, las cuales se muestran enajenadas por la litis en sede estatal, por la mentalidad de llevar a otro a juicio, a sabiendas que el índice de credibilidad y confianza en la justicia peruana asciende al 82\% al año 2017 según el Latinobarómetro ${ }^{1}$; que el índice de corrupción en la justicia peruana se eleva al 8.2 de un máximo de $10^{2}$; y que el índice de desaprobación en la justicia peruana al mes de marzo de 2018 asciende al 71\% según Ipsos ${ }^{3}$.

En el plano regional, la confianza en el Poder Judicial no pasa del 50\%, según el índice total por país al año $2017^{4}$, en el que se aprecia que en

\footnotetext{
1 Fuente Perú de LATINOBAROMETRO: http:// www.latinobarometro.org/LATDocs / F 00006433 InfLatinobarometro2017.pdf

2 Fuente Perú de LATINOBAROMETRO: http:// www.latinobarometro.org/LATDocs / F 00006433 InfLatinobarometro2017.pdf

3 Fuente Perú de IPSOS: https://www.ipsos.com/sites/ default/files/ct/news/documents/2018-03/opinion-datamarzo-2018.pdf

4 Fuente LATINOBARÓMETRO: https://intal-alianzalb.iadb.
} org/InformeLatinobarometro_2017.pdf - Pagina 35. los casos de Costa Rica y Uruguay, el extremo más alto, se sitúa en 43 y 41 respectivamente, mientras que en los casos de Perú y Paraguay, los extremos más bajos, se sitúa en 18 y 15 respectivamente.

Similar situación se da con el problema de la corrupción en Latinoamérica al año 2017 , en donde según el Latinobarómetro ${ }^{5}$, Brasil, Colombia y Perú, en el extremo más alto, aparecen con 31,20 y 19 respectivamente, mientras que en el extremo más bajo aparecen Costa Rica y Uruguay con 6 y 1 respectivamente.

Estas consideraciones permiten deducir razonablemente que el sistema de justicia carece de legitimidad y su funcionamiento no es idóneo para la solución de los conflictos intersubjetivos de intereses de la población, fundamento más que suficiente para promocionar, fomentar y empoderar los medios alternativos de resolución de conflictos, en especial el arbitraje, que es una jurisdicción privativa por mandato constitucional en el Perú, conforme lo dispone el artículo 139 inciso 1 de la Constitución, que la ha establecido como una jurisdicción independiente, por excepción, lo cual es razón bastante para que lo decidido en sede jurisdiccional arbitral no deba ser impugnado en sede judicial ordinaria de la que tanto desconfía la ciudadanía y, por el contrario, sus decisiones sean self executing o autoejecutables, sin necesidad de recurrir a la autoridad judicial ordinaria, esto es, dotar al arbitraje de poder de ejecución, del carácter obligatorio a su mandato, de tener coacción para que se cumpla el interés tutelado sobre el cual ha recaído la jurisdicción por voluntad de ley, sin el cual carecería de realización práctica, máxime si la ejecutabilidad de una decisión, en su desarrollo material, tiene más de administración que de jurisdicción.

Por otro lado, en el arbitraje, las partes eligen el lugar, las reglas y también a un tercero imparcial para que decida sobre el caso que se le presenta, a través de una decisión denominada laudo arbitral, que equivale a una sentencia en el proceso judicial de resolución de conflictos. Este medio es una forma de justicia privada, no estatal, aunque no es directa porque no es auto compositivo sino hetero compositivo.

\footnotetext{
5 Fuente LATINOBARÓMETRO: https://intal-alianzalb.iadb.org/ InformeLatinobarometro_2017.pdf - Pagina 34 y 35
} 
La diferencia con la mediación consiste en que el arbitraje es un medio más formal, por cuanto las partes no conservan la responsabilidad y el control del proceso, sino que se lo transfieren al árbitro; está basado en derechos porque se resuelve conforme a ley, mientras que la mediación está basada en intereses; y las partes dirigen sus fundamentos $\mathrm{y}$ argumentos al árbitro, no a la otra parte como en la mediación. Es, evidentemente, una forma democrática que privilegia la privacidad del litigio y su esencia voluntarista, en la que siempre está presente la posibilidad de llevar adelante una conciliación para terminar con el conflicto. El prestigio del arbitraje dependerá, en todo caso, de la competencia especializada y la ética del árbitro. Sus bondades, problemas y eficacia son tratados más adelante.

Todos estos medios alternativos expresan una cultura democrática y de educación para la paz, signada por el debate, el escrutinio y la crítica abierta de los intereses en conflicto, los cuales experimentan una transformación evolutiva facilitando relaciones cooperantes $y$ no impositivas en un plano de igualdad de partes.

\section{EVOLUCIÓN, NATURALEZA, BONDADES Y ÉTICA EN EL ARBITRAJE}

\section{Origen y evolución del arbitraje}

De antiguo han existido diferentes formas de resolver los conflictos, unos de carácter formal y obligado, tal es el caso del proceso judicial estatal; y otros facultativos que constituyen la alternancia a aquel y son la negociación, la mediación, la conciliación y el arbitraje, de los que se han referido notas generales precedentemente.

Históricamente, como señala Montalvo, J. (2009) el arbitraje es previo a la existencia del estado, porque es connatural al hombre el conflicto intersubjetivo y ha existido $a b$ initio. Entonces, siendo el estado una realidad artificial creada por el hombre, la composición de conflictos en manos de terceras personas, imparciales y privadas (los árbitros), existió desde el inicio de la humanidad hasta la creación del estado, habiendo sido retomada una vez que la jurisdicción estatal comienza a ser desbordada por la carga procesal y la corrupción, cayendo en la consideración social.
Vidal, F. (2006, pág. 54) considera que:

el arbitraje no ha sido creación romana, pues puede sostenerse que ha existido desde la más remota antigüedad. Se origina con el sedentarismo de los seres humanos y la toma de conciencia de organizar su vida de relación dentro del grupo y también en la necesidad de confiar en un tercero la solución de sus conflictos. Puede afirmarse, por ello, sin hesitación alguna, que el arbitraje es anterior a la organización formal de la administración de justicia y que en su origen no constituyó una alternativa, sino que fue un medio de solución de controversias anterior a la autoridad estatal.

La explicación pertinente de Vera, G. (2013) es obvia: antes de la creación de los Estados, a alguien se le tenía que encargar la resolución de las disputas, razón por la cual era el anciano venerable, el sacerdote o alguna otra persona de gran ascendencia quien fungía de árbitro y cuya decisión era respetada por los contendientes, quienes se comprometían a acatarla.

Por otra parte, Fernández, A. (2012) anota que (en el pasado) el arbitraje y las normas jurídicas han compartido el protagonismo en la resolución de disputas; aquel data del siglo VIII a. C. en Roma, en donde se utilizaba como instrumento en la solución de controversias mercantiles, aun cuando el árbitro actuaba entonces más como un mediador que servía como amigable componedor en las disputas, que como un decisor.

Asimismo, señala Fernández, L. (2016) que el arbitraje aparece en el "Digesto" como un sistema parecido al proceso jurisdiccional que se fundaba en el "compromissum", esto es, la voluntad de las partes de someterse a un arbitraje; y en el "receptum arbitrii", es decir, lo recogido por el propio arbitro para definir la recepción de la decisión de tal modo que resulte inapelable por las partes. (D.4.8.27). Más aun, la similitud entre los jueces y árbitros era tal que éstos fueron denominados como "iudices compromisarii" según aparece en los edictos o Novelas de Justiniano (N.58.11).

Es previsible, dado el apogeo mercantil en la Alta Edad Media, que los conflictos sobre asuntos mercantiles se resolvieran con celeridad para no afectar el movimiento económico, de allí que su resolución estaba a cargo de los más interesados y conocedores de la materia, que eran los gremios, que formaban unos tribunales especiales propios y autónomos de la justicia 
en los países iberoamericanos

The need to empower arbitration as a private jurisdiction in

the ibero-american countries

real. Es sabido que en esa época la justicia se administraba por fueros.

Conforme señala Merchán, A. (1981) en España, concretamente el "Liber iudiciorum" de los godos mencionaba expresamente el arbitraje; en el Fuero Juzgo, en los reinos de Castilla y León, se permitía la elección de acudir al arbitraje, así como en los fueros municipales como los de Zamora y Salamanca; y en el Fuero Real y en la Tercera Partida se normaba el arbitraje.

En tiempos más modernos, la Constitución de Cádiz de 1812 recoge el arbitraje y la conciliación como un derecho constitucional. En el Perú el arbitraje es considerado como una jurisdicción privativa recién por la Constitución de 1979.

Estos antecedentes nos mueven a preguntarnos si la constitucionalización del arbitraje es necesaria. Es de considerar que la opción de acudir al arbitraje forma parte de un derecho fundamental de la persona humana, como es la libertad, en virtud del cual nadie está obligado a hacer lo que la ley no manda ni impedido de hacer lo que ella no prohíbe, razón por la cual no se aprecia una necesidad especial de establecer como un derecho humano poder elegir el arbitraje.

En cambio, parece una consideración más importante y directa, a efectos de dotar de fuerza al arbitraje, considerarla una jurisdicción privativa, pues esto constituye una excepción al principio de unidad y exclusividad del sistema de justicia estatal. De esta manera, se le coloca en el mismo nivel aunque sin formar un sistema.

Además, así el ciudadano puede optar por esta jurisdicción privativa en ejercicio de su derecho a la libertad. Importa adelantar, no obstante, que el problema de origen del arbitraje, si nace en la Constitución o en una ley, si se origina como jurisdicción o como un derecho fundamental de la persona, con ser importante, no lo es todo.

En efecto, resulta igualmente importante la regulación normativa de rango legal para el buen funcionamiento del arbitraje, siendo de destacar que aquí sí se puede apreciar la mayor conveniencia de considerar al arbitraje como una jurisdicción privativa, pues es imprescindible que se le reconozca todos los atributos de una jurisdicción, a fin de que no tenga necesidad de recurrir a la justicia estatal para ejecutar sus laudos o para que resuelva la impugnación de sus decisiones, aspectos que constituyen problemas de la operatividad del arbitraje en el Perú y que se analizarán más adelante.

En la post modernidad, caracterizada por la globalización y el neo liberalismo, las corporaciones trasnacionales y los grandes contratos de inversión, el arbitraje se ha convertido en una herramienta sumamente útil para resolver conflictos de intereses patrimoniales, que de otro modo se agravarían con la intervención de la justicia estatal, plagada de dilaciones interminables, laberintos procesales kafkianos, hiper carga procesal, corrupción generalizada y una soberbia incompetencia funcional.

La idea central del arbitraje es, sin duda, poner al alcance de las personas, naturales y jurídicas, la posibilidad de encontrar solución a su conflicto de manera célere y ajustada a derecho. Sin embargo, el arbitraje en los países iberoamericanos enfrenta algunos problemas que restan posibilidades de aspirar a una decisión oportuna y justa debido a la eventualidad de recurrir a la justicia estatal en vía de impugnación o para ejecutar el laudo.

\section{E1 inicio de la supremacia e influjo de la jurisdicción estatal}

En el siglo XIII ocurrió en Europa que el Estado confiscó el conflicto a la víctima, al realizarse un cambio significativo en las relaciones de poder en la sociedad, como advierte Anitua, G. (2015). Desde entonces, la determinación de la verdad legal a través del proceso judicial se hizo mediante el método oficial que el estado adoptó como parte dominante sobre el súbdito dominado. Ello selló definitivamente la forma de ejercer el poder y el control social, pues la autoridad estatal, entonces absolutista, podía dictar leyes y aplicarlas a través de sus jueces, lo que podía cambiar las relaciones sociales.

Los jueces y la policía como funcionarios del rey, surgen por la necesidad de especialización que exigía este nuevo atributo estatal de ejercer el poder y el control, con lo cual, señala Anitua (2015), el derecho se instrumentalizó al servicio de la autoridad al asignar un patrón de criterio pre establecido en función de las 
leyes sancionadas por el propio estado. Luego llegó la profesionalización y burocratización como órganos institucionalizados encargados de administrar la justicia desde el Estado, siempre desde la cúspide del poder, haciendo prevalecer desde entonces las ideas de orden y justicia, en vez de la idea de libertad -de la que se nutre el arbitraje- como consecuencia de la expansión de los estados y su conversión en formas organizativas concentradas, forma que requería de una organización dirigida por una autoridad central soberana.

El mantenimiento de un poder político unificado era el objetivo, para lo cual se reclutaban funcionarios instruidos para discernir justicia penal en nombre del monarca y ejercer violencia legitimada. El modo cómo los funcionarios profesionales discernían justicia, originó un discurso o pensamiento racionalizador, que cerró el círculo de dominación consistente en idea y acción para un mismo fin. El fin era -y sigue siendo- que el estado reemplace al ciudadano en el conflicto intersubjetivo y a la sociedad unida en asamblea para favorecer la resolución del conflicto.

Esa manera hegemónica de administrar justicia, de arriba hacia abajo, para graficarlo espacialmente, no horizontalmente como es aconsejable, demostró que el conflicto en sí mismo ya no importaba, sino la falta de respeto a la ley de la autoridad soberana. Por eso intervenía el estado en el conflicto particular, para hacer ver y creer que como autoridad debe discernir el conflicto y solucionarlo, presentándose como una especie de tutor de las personas a las que, desde entonces, no se les quiere reconocer su mayor capacidad y mejor interés en comprender y desentrañar la mejor manera de favorecer la resolución del conflicto. Esto es precisamente lo que revela la jurisdicción arbitral.

La vinculación entre el poder político y el poder económico es, desde entonces, inocultable a través de la jurisdicción estatal, para conservar su posición de dominio privado.

Pavarini, M. (2010) anota que a partir del siglo XVI hasta el siglo XVIII, un fenómeno económico social denominado acumulación originaria, genera en la segunda mitad del siglo XVIII la revolución industrial, la cual pone fin al viejo orden socio político feudal e instaura un nuevo orden capitalista, caracterizado por la libertad del ciudadano como condición indispensable para su actividad comercial e industrial, que le permitía despojar a las clases productoras de los medios de producción $\mathrm{y}$, con ello, afectar su sustento, por lo que se volvieron una fuerza de trabajo asalariada a la que había que disciplinar para que acepten su condición como natural e irreversible, a fin de que la burguesía conserve su poder.

El discurso racionalizador fue, en esta ocasión, el contrato social, que pretendió justificar la existencia del estado en un mito: el pacto tácito de los hombres que viven en sociedad, por el cual cambian una porción de libertad por un orden social administrado por la autoridad estatal, que de esa manera se erige y mantiene como el único titular del poder. El liberalismo permaneció durante los siglos XIX y XX pretendiendo hacer creer que traía consigo la igualdad de los hombres, sin embargo ello no fue así y solo conllevó injusticia, discriminación y exclusión social, que se agudizaron en las postrimerías del siglo $\mathrm{XX}$ con el neo liberalismo, es decir, con la hipérbole de la libertad económica y el ocaso de las demás libertades.

Entretanto, el ejercicio del poder de administrar justicia continúa en manos del estado en estrecha vinculación con el poder económico, con el concurso de profesionales abogados que se alejan del sentido común, el sentido de justicia y del conocimiento del género humano, merced a su apego a dogmas jurídicos alejados del verdadero titular del poder jurisdiccional que es el pueblo, como constitucionalmente está establecido.

En la alucinación estatal de que el poder de administrar justicia emana del pueblo hemos llegado al siglo XXI en esta región latinoamericana, negando al arbitraje la categoría de jurisdicción constitucional en la mayoría de los países iberoamericanos y, cuando se le reconoce constitucionalmente, como en el caso del Perú, se le recortan dos fundamentales atributos de toda jurisdicción: el imperium y la coertio.

\section{Naturaleza jurídica del arbitraje}

Cuando nos referimos a los medios alternativos de resolución de conflictos, especificamos que el arbitraje es uno que consiste en que un tercero resuelve una diferencia que divide a dos o más 
en los países iberoamericanos

The need to empower arbitration as a private jurisdiction in

the ibero-american countries

partes, en ejercicio de la misión jurisdiccional que le ha sido confiada por ellos. Aparece aquí una primera característica tributaria de su esencia, como es el carácter voluntario del arbitraje. Asimismo, se puede advertir una segunda característica, cual es aquella que concibe al árbitro como un juez privado designado por las partes en conflicto para que decida al respecto. Ambos caracteres nos permiten extraer un tercer elemento esencial, este es el rasgo institucional. En efecto, el ser un medio alternativo es apenas una señal de índole técnica procedimental si se quiere, pero el hecho de que el arbitraje posea un régimen constitucional, lo identifica y caracteriza como una institución idéntica a la judicatura estatal, salvo en el origen.

Precisamente, al ser una institución análoga y equivalente a la justicia estatal, su naturaleza es la de una jurisdicción con todos los atributos de ésta. Hacen bien, entonces, las constituciones como la peruana, en nominarla como una jurisdicción privativa de excepción, pero hacen mal la normatividad legal que, también como la peruana, no le otorgan todos los atributos jurisdiccionales, como el imperium y la coertio, de las que carece el árbitro. Esta preterición constituye un problema que limita la función y eficacia del arbitraje, del que emana la eventual intervención de la justicia estatal, restringiendo la efectividad del arbitraje, como lo veremos más adelante.

La naturaleza del arbitraje es, pues, diferente a la de la mediación y la conciliación, en las que si bien interviene un tercero, éste no decide sobre el conflicto, pues son las mismas partes las que, con la ayuda y sugerencia de aquellos, lo resuelven.

Asimismo, es distinta a la figura del mandatario con que se ha querido asimilar al árbitro, en razón de que recibe un encargo, como es el de decidir acerca del conflicto, pero la diferencia está en que en el contrato de mandato el mandatario recibe instrucciones de los mandantes para realizar el encargo, mientras que en el arbitraje el árbitro si bien se constituye como juez privado por la voluntad de las partes, es autónomo en su decisión, sin que las partes puedan instruirlo sobre la forma cómo debe resolver el conflicto.

También es diferente a la figura de la transacción, que aun cuando es voluntaria y constitutiva de cosa decidida con efectos de cosa juzgada como el arbitraje, no interviene un tercero, pues las partes se hacen concesiones recíprocas, lo que no ocurre en el arbitraje, en el que un tercero designado por las partes decide el conflicto sin que las partes se hayan concedido nada.

En consecuencia, el arbitraje tiene una naturaleza sui géneris. Es jurisdiccional en aquellos países cuya Constitución Política lo establece como una jurisdicción privativa, lo cual desde mi posición, no le niega carácter de jurisdicción originaria, pues la potestad de administrar justicia emana del pueblo, según lo dispone la Constitución y, en ese sentido, la forma que asuma la administración de justicia, estatal o privada, dimana en todo caso del pueblo. Más aun, la justicia togada estatal es, más bien, delegada porque el pueblo elije a un organismo constitucionalmente autónomo para que seleccione y nombre a los magistrados, mientras que en el arbitraje un ciudadano especializado directamente elegido por los ciudadanos involucrados en un conflicto, lo resuelve. Hay un paralelismo con la justicia por jurado, en donde el propio pueblo decide un caso.

Sostener en contrario, que la naturaleza del arbitraje es contractual, no agota el análisis. La existencia de un contrato o acuerdo de voluntades en un compromiso arbitral es, en todo caso, la expresión de la potestad del pueblo en decidir en su mismo seno un conflicto, eligiendo al decisor. Una prédica similar llamada la teoría del contrato social, se utiliza para justificar a la justicia estatal y las demás funciones del Estado y no por ello se pretende atribuir naturaleza consensual a aquella. Se aprecia, entonces, que la voluntad autónoma del pueblo expresa el poder que posee para discernir justicia bajo el sistema estatal o privado, con arreglo a Derecho, lo que lo diferencia de la justicia popular, que es por mano propia, ajena y contraria al orden jurídico.

El problema, que desarrollaremos más adelante, es que el árbitro no tiene imperium ni coertio, lo cual es un recorte severo a sus facultades, que no corresponde a su naturaleza jurisdiccional que le reconocemos y, más bien, abonaría a su naturaleza contractual. El motivo para que esto ocurra es que el Estado moderno, desde el siglo XIII, monopoliza la jurisdicción 
para ejercer control y dominación, por lo cual no reconoce al árbitro la potestad de realizar inspecciones, examinar coactivamente testigos ni que sus decisiones sean self executing.

¿Qué clase de jurisdicción constitucional es entonces el arbitraje? En el caso del Perú, el artículo 139 inciso 1 dispone claramente que se trata de una jurisdicción de excepción, porque la general es la estatal y, por cierto, no le señala ninguna limitación, sin embargo la ley general de arbitraje si lo hace, privándolo de imperium y de coertio, distinguiendo donde la Constitución no lo hace, como tampoco establece la Constitución que la justicia estatal sea la única que puede ejecutar sus fallos. En efecto, algunas decisiones administrativas, como las de la Superintendencia de Administración Tributaria y las de las municipalidades, cuentan con sus propios ejecutores coactivos para su cumplimiento y realización.

Esta situación no tiene otra explicación que la tendencia hegemónica del Estado que pretende, contra natura, privar al titular del poder que es el pueblo, de ejercer su potestad de administrar justicia, como lo reconoce la propia Constitución en el artículo 139. Nuevamente se advierte el paradigma de que el poder solo lo tiene el funcionario público como autoridad del Estado. Ergo, el árbitro es un ciudadano, un particular, por lo que su decisión no es ejecutable por sí misma, cuando se sabe que se trata de un poder delegado por el pueblo, que es un ciudadano que está investido de autoridad temporalmente, para un caso determinado, por las partes con el reconocimiento constitucional del estado. Empero, al árbitro se le ve todavía como un privado que realiza funciones para privados, no en interés público. En el hipotético caso que ello fuera así, discreparíamos de este enfoque pues la resolución de conflictos entre particulares abona al interés público.

En aquellos otros países donde aún se le trata y regula como un medio alternativo de resolución de conflictos, la naturaleza del arbitraje es la de la libertad y autonomía de la voluntad, pues las partes elijen las reglas y los terceros a los que dotan de autoridad para dirimir su conflicto.

Concluyentemente, para nosotros la naturaleza del arbitraje es de una peculiaridad y autonomía singular, en la que se expresa de mejor manera la resolución de conflictos de las personas, cosa que la justicia estatal no hace, incumpliendo su misión teleológica hacia el logro del bienestar general y la seguridad integral. Limitar el arbitraje a un aspecto contractual es simplemente alejarse, como dice Lorca, A. (2008) de las soluciones atinentes a la resolución dentro de un proceso (arbitral) de la controversia. De la misma manera, identificarlo solamente con la judicialidad sería fijarse en el aspecto externo de la forma utilizada para arribar a la solución del conflicto, que no justificaría la contraposición o la antítesis metodológica.

La naturaleza especialísima del arbitraje viene dada por la respuesta actual del estado de reconocer el clamor ciudadano de tener una alternativa mejor que la jurisdicción estatal para la solución de sus conflictos, que no es posible negar por la potestad que tiene el mismo pueblo de administrar justicia y resolver en Derecho sus conflictos con mayor celeridad y certeza que el estado, el que si bien en algunos países le confiere rango y jerarquía de jurisdicción excepcional, no obstante le niega ejecutividad propia a sus decisiones, por lo que en la praxis restringe y esteriliza al arbitraje, haciéndolo depender de la justicia estatal en ciertas eventualidades y fundamentalmente en caso de incumplimiento.

\section{Valia y preeminencia del arbitraje}

La sociedad se asienta sobre el conflicto, no sobre el consenso general. Es el conflicto el que permite que la sociedad avance en la medida que va resolviendo las divergencias y diferencias, superando el clima de tensión que la conflictividad produce. Simular un consenso general, en cambio, ocultando los conflictos existentes, originaría el agravamiento de la conflictividad y su estallamiento en violencia y criminalidad, con lo cual el Estado vería afectado el cumplimiento de sus dos fines esenciales, como son el bienestar general y la inseguridad integral, que son interdependientes y complementarios, como ya se ha dicho en la introducción de este artículo.

De tal modo que el Estado debe fomentar la prevención de conflictos en virtud a una política pública integral que cree las condiciones adecuadas para que las personas privilegien la convergencia antes que el disenso; pero también debe propender a su resolución racional a través de los medios existentes, como son la justicia estatal y la justicia privada, a 
en los países iberoamericanos

The need to empower arbitration as a private jurisdiction in

the ibero-american countries

fin de evitar que las pretensiones discordantes colisionen con violencia y lleguen a imponerse por métodos intimidantes directos. En este orden de pensamiento, la justicia es un medio para alcanzar la paz social que es el fin.

En ese sentido, ambas alternativas de justicia tienen el mismo fin y presupuestos epistemológicos, por lo que cabe discernir acerca de la valía y la preeminencia de una sobre la otra para resolver los conflictos intersubjetivos de intereses.

A tal efecto, el sistema de justicia más idóneo en nuestra región es el privado, pues la corrupción institucional, la falta de confianza en la autoridad pública, la excesiva carga procesal, la dilatada duración de los procesos, el excesivo costo en tiempo y economía que supone, la incompetencia de los órganos jurisdiccionales que se traduce en fallos ininteligibles o insólitos y la sobre exposición mediática de los casos en este ámbito, han erosionado la celeridad, certeza y seguridad jurídica del sistema jurisdiccional estatal y afectando su independencia e imparcialidad, como se da cuenta en los datos estadísticos referidos en el ítem 2.2, página 6 .

En cambio, el sistema de justicia privada no está afectado por esas carencias y deficiencias, pues el o los árbitros son elegidos por las partes en conflicto, por su prestigio de experto y especialista imparcial e independiente, cuyas decisiones no solo serán apreciadas por su oportunidad y precisión, sino por su sentido de justicia garantista al que la voluntad de las partes se subordina en aras de lograr el encuentro de la verdad de los hechos, esto es, una verdad que corresponda a los hechos mismos, como sostiene con propiedad Lorca, A. (2001).

Un punto adicional importante a favor del sistema de justicia privada, que denota su mayor mérito y preferencia respecto de la justicia estatal, lo constituye el hecho de que la propia jurisdicción estatal da por terminado el proceso seguido en su ámbito si es que las partes realizan un acuerdo judicial o extrajudicial resolviendo el conflicto, lo que connota el privilegio de la forma privada de resolver los conflictos por encima de la forma pública. En efecto, el artículo 321 del Código Procesal Civil del Perú señala que el proceso concluye sin declaración sobre el fondo, entre otras causales, cuando se sustrae la pretensión del ámbito jurisdiccional. Evidentemente esto puede ocurrir por la decisión común de las partes de llevar el caso a la justicia privada (arbitraje).

Asimismo, el artículo 323 del mismo Código señala que las partes pueden conciliar ante el juez su conflicto de intereses en cualquier estado del proceso; y el artículo 334 del código acotado establece que también en cualquier estado del proceso las partes pueden transigir su conflicto de intereses. Si bien en estos dos casos hay una referencia explícita a medios de solución de conflictos alternativos a la justicia estatal, distintos al arbitraje, es revelador del respeto de la justicia estatal por la solución racional y directa de los conflictos por las partes.

Otro aspecto relevante a favor del arbitraje es su flexibilidad, a diferencia del sistema de justicia estatal. En efecto, basado en el principio de autonomía de la voluntad y libre decisión de las partes, éstas pueden convenir sobre la elección de o los árbitros, el lugar del arbitraje y el procedimiento al que se hayan de ajustar los árbitros en sus actuaciones, incluso su duración, así como el plazo, forma, contenido y notificación del laudo. Como se puede apreciar el sistema de justicia privada se fundamenta en el principio de auto determinación personal, como indica Maluquer, C. (2001), el cual define su propia independencia y libertad y dispone acerca del uso y goce de sus propios derechos y facultades, creándolos, modificándolos y extinguiéndolos.

Es preciso subrayar que, evidentemente, es la voluntad de las partes la que origina el arbitraje, pero sus efectos no dependen directamente de ello, sino de la propia naturaleza de la institución arbitral, que obviamente encuentra sus límites en las materias no dispositivas, como son los casos de derechos humanos y los casos penales, en los que el sistema de justicia privada no puede servir, por lo menos por ahora, como solución a cualquier caso o controversia, como señala Cremades, B. (2001), siendo ésta una actual limitación en el que se reconoce una desventaja respecto de la justicia estatal, según opinión del articulista. Sin embargo, frente al cúmulo de ventajas en orden a la mayor celeridad, certeza y seguridad jurídica dl arbitraje, su taxativo ámbito de aplicación considero que no implica mayor desventaja. 
En efecto, desde que existen modelos de justicia penal no togados, como el de jurado y el escabinado, no es impensable que en un futuro que se alcance la descriminalización de algunas conductas, como los delitos contra el honor o las lesiones leves u otros delitos de bagatela, la justicia privada pueda conocer y discernir de algunos casos ilícitos, sobre todo si se toma en cuenta los mejores criterios de indemnización que se manejan fuera del sistema judicial estatal y que frente al daño infligido es lo que merece mayor atención, pero que lamentablemente en el sistema jurisdiccional estatal no es así, pues lo que concita el interés del estado no es la resolución del conflicto sino la imposición de castigo por el quebrantamiento de la norma estatal, lo cual relega a un plano ínfimo los derechos de la víctima $\mathrm{y}$, por el contrario, exalta la intervención del estado para sus propios intereses de ejercer el ius puniendi selectivamente $y$, en esa línea, ejercer control y dominación en la sociedad respecto a los grupos marginales, carenciados y vulnerables.

En definitiva, frente a la crítica situación de la jurisdicción estatal, que no es transitoria sino estructural por la gravedad y cantidad de las deficiencias que exhibe y que le han valido, en los países iberoamericanos, la desconfianza y descrédito ante la ciudadanía, un sistema de justicia privada como el arbitraje tiene, a juicio del suscrito, méritos bastantes y suficientes para resolver conflictos intersubjetivos de intereses de manera más segura que la jurisdicción estatal.

El fundamento último de esta apreciación objetiva es que, al final, el mismo titular del poder, que incluye por cierto, la potestad de administrar justicia, es el que discernirá justicia como representante del pueblo entre sus miembros, sin el estigma burocrático de formar parte de una élite jurisdiccional que con sus decisiones se aleja cada vez más del entendimiento del pueblo y sobre la cual existe la idea históricamente sostenida de que al formar parte de un aparato estatal no pierden de vista la alineación de sus actuaciones para satisfacer políticas gubernamentales de turno, para posibilitar la satisfacción del órgano administrador del estado de donde proviene el presupuesto; de ahí la necesidad de empoderar al arbitraje como una plena jurisdicción privada de carácter excepcional, como lo reconoce la Constitución peruana, a fin de que pueda ejercer plenamente todos los atributos de la jurisdicción, como los de imperium y el de coertio, de los que carece.

\section{ÉTICA Y ARBITRAJE}

La adecuación y conformidad de nuestros actos a la ética es, hoy en día, un problema que se hace más difícil afrontar debido al nuevo orden mundial, caracterizado por la globalización y la tecnología que exaltan un estilo de vida epicúreo $\mathrm{y}$ hedonista, de permanente e inacabada satisfacción de necesidades artificiales, suntuarias y de recreación, implantadas en el cerebro humano a través del uso intensivo de una programación neurolingüística, que hace depender el comportamiento de experiencias incentivadas por el lenguaje aplicado a los procesos neurológicos. De hecho, el cogito ergo sum de Descartes, base de la filosofía racionalista occidental, ha mutado al tengo luego soy.

Ya en "La rebelión de las masas" el ilustre José Ortega y Gasset ${ }^{6}$ nos presenta su concepto de hombre-masa, aquella persona afincada en la holgazanería hedonista debido a la comodidad de que disfrutaba, por lo que pensaba únicamente en su bienestar, para aseverar que el mundo sufre una grave desmoralización, producto de un proceso de desorientación, debido a una anemia cultural que lo orienta exclusivamente hacia el consumo.

En la actualidad, ha sucumbido la cultura de los valores, ha ocurrido el quiebre de los principios y se ha entronizado la (in) cultura de lo efímero y lo provisional, lo utilitario y lo que produce satisfacción instantánea, lo cual afecta gravemente el ejercicio de la ética en la vida privada, pública y profesional.

Esto es de especial importancia para la institución del arbitraje, como medio privado de ministrar justicia, pues constituye la principal desventaja de la jurisdicción estatal y el origen de la pérdida de su credibilidad y confianza populares.

Es un axioma que muy poco el resultado depende del sistema, sino más bien de los hombres que lo hacen funcionar, siendo así, la justicia arbitral por sí sola no garantiza la imparcialidad ni la objetividad en la resolución del conflicto.

6 Disponible en https://filosofiauacm.files.wordpress. com/2010/02/jose_ortega_y_gasset_-_la_rebelion_de_las_ masas.pdf 
en los paises iberoamericanos

The need to empower arbitration as a private jurisdiction in

the ibero-american countries

Si en efecto, el arbitraje se basa en la confianza, el apego funcional a la ética profesional por parte de los árbitros reviste capital importancia, ya que sirve para mantener su dignidad y el prestigio de la jurisdicción arbitral.

Los principios éticos de los que no debe separarse el árbitro son la independencia, la imparcialidad, la revelación, la comunicación con las partes, la confidencialidad, la diligencia y la lealtad a los valores y principios que encarna la justicia arbitral.

En lo que respecta a la independencia, significa que el árbitro debe mantenerse alejado de toda influencia y no permitir intervención alguna en su ejercicio jurisdiccional. Precisamente, una de las formas de contrarrestar la posibilidad de intrusión o influjo es la elección y selección de los árbitros, que depende exclusivamente de las partes, por lo que es de suponer que ambas no elegirían árbitros carentes de ética. Las partes deben escrutar los vínculos cercanos, esenciales, nuevos y acreditados que pueden tener los árbitros, sea con terceros ajenos o con otros árbitros, a fin de cautelar el principio de independencia.

Aquí el origen del sistema repercute favorablemente en su operatividad ética, sin embargo, la posibilidad de que la ética esté ausente en el desempeño de un árbitro elegido por las partes con base en sus limpios antecedentes, siempre existe, pero la corrección de dicha contingencia gracias a la denuncia y la sanción moral inhabilitadora mantiene el correcto funcionamiento del sistema arbitral. Las partes escogen a los árbitros. La justicia estatal no permite que elijas a los jueces. La diferencia es obvia y ventajosa a favor de la jurisdicción arbitral.

Otra forma de neutralizar el riesgo de una falta de ética es la alternancia de los árbitros para no generar usuarios fijos de tal o cual árbitro, lo cual se corresponde con la cantidad impar del tribunal arbitral.

En lo concerniente a la imparcialidad, significa la garantía de que el árbitro no ha de ser parte en el proceso a su cargo y no tiene ningún interés en el objeto del mismo ni en su resultado, por lo que su decisión es objetiva y libre de prejuicios o favoritismos.
El Reglamento de Arbitraje de la $\mathrm{CIADI}^{7}$ señala que los árbitros deben gozar de amplia consideración moral (...) e inspirar plena confianza en su imparcialidad de juicio.

El Reglamento de Arbitraje de la Ley Modelo sobre Arbitraje Comercial Internacional ${ }^{8}$, aprobado por la Comisión de las Naciones Unidas para el Derecho Mercantil, señala que el árbitro no debe dar lugar a dudas justificadas acerca de su imparcialidad o independencia, para que pueda ser elegido.

Respecto al deber de revelación, el árbitro tiene el deber de informar, desde el primer momento que le sea posible y hasta la culminación del proceso arbitral, acerca de cualquier situación, hecho o circunstancia que pueda colocar en duda su independencia e imparcialidad en relación a las partes; así lo señalan las Reglas Éticas sobre arbitraje internacional de la International Bar Association (IBA) ${ }^{9}$.

En caso que el árbitro no cumpliese con este deber ético de revelación, su laudo incurriría en causal de nulidad, generando responsabilidad del árbitro.

Acerca del principio de comunicación, es el deber que tiene el árbitro de comunicarse con ambas partes y no solo con una de ellas cada vez que reciba informaciones o antecedentes que sirvan a la resolución de la controversia, como lo señalan las normas antes referidas, excepto cuando se trate de resolver cuestiones de procedimiento o cuando ambas partes son citadas a una audiencia y sólo comparece una de ellas, o en el evento en que ambas partes autoricen que este tipo de comunicaciones se efectúen.

En un sentido más amplio, pero igualmente ético, se indica que los árbitros no deben aceptar regalos o ser objeto de mucha hospitalidad directa o indirecta de una de las partes y deben evitar tener vida social o contactos profesionales con una de las partes.

El deber de confidencialidad significa que el árbitro no puede utilizar las informaciones a que tuvo acceso durante el proceso arbitral para obtener ventajas personales o para favorecer

\footnotetext{
7 Disponible en: https://icsid.worldbank.org/sp/Pages/ icsiddocs/ICSID-Convention-Arbitration-Rules.aspx

8 Disponible en: https://www.uncitral.org/pdf/spanish/ texts/arbitration/ml-arb/07-87001_Ebook.pdf

9 Disponible en: http://revistas.pucp.edu.pe/index.php/ iusetveritas/article/view/14817/15373
} 
o perjudicar a terceros, como lo señalan las Reglas de Ética de la IBA y el Código de Ética de la AAA.

Sobre el deber de diligencia, las Reglas de Ética de la IBA señalan que el árbitro debe emplear sus mejores esfuerzos para conducir el arbitraje en forma diligente, eficiente y en el menor tiempo posible, con el objeto de obtener una solución justa del conflicto, pues constituyen el mejor freno contra la dilación en el proceso arbitral; y el Código de Ética de la AAA señala que el árbitro debe llevar a cabo el proceso en forma ecuánime y diligente, es decir, cumplir con sus obligaciones en forma diligente y concluir el arbitraje a la mayor brevedad posible, conforme lo permitan las circunstancias del caso, debiendo aceptar el cargo únicamente si puede darle el tiempo y la atención que las partes razonablemente esperan.

Como se puede apreciar, el cumplimiento personal de los árbitros de las reglas antes citadas, hace posible su rectitud, probidad e integridad, en términos de imparcialidad, independencia, competencia, diligencia y discreción, para salvaguardar la confianza y conservar la reputación de la jurisdicción arbitral, para lograr que se siga desarrollando como uno de los mecanismos más idóneos de solución de conflictos en la vida actual.

Empero, la mala práctica arbitral es un riesgo que está presente, sobre todo por la trascendencia económica de los conflictos sometidos a arbitraje, aspecto este que es resaltado por Guzmán-Barrón, César; Zúñiga Rigoberto; y Seminario Carlos (2016) sobre la base del estudio realizado por la Contraloría General de la República del Perú durante el periodo 2003 al 2013, el cual analiza 2,796 arbitrajes, con una pretensión total de S/. 2'307'188,236.00, habiendo los árbitros dispuesto un desembolso de S/. 1'128'280,981 a favor de los privados, por pago de contraprestaciones, pago de mayores gastos generales, enriquecimiento sin causa, penalidades, indemnizaciones, entre otros.

Naturalmente, el modus operandi de los malos árbitros no dejará rastros de las malas prácticas, no obstante, de acuerdo con Ezcurra, H. (2015), se pueden advertir las situaciones siguientes: La preferencia por un árbitro determinado; el árbitro que da su opinión antes y con la finalidad de ser designado; el árbitro que informa a quien lo designó cómo va el caso, brindándole consejos para una mejor defensa; y el árbitro venal a quien se le designa por su parcialidad; entre otros especímenes que hay que evitar se propaguen para no dañar la institución arbitral, la cual debe ser entendida y considerada como una jurisdicción, con todo lo que ello significa en términos de institución pública servida por personas privadas, pero con un interés público, cual es el de resolver los conflictos en justicia.

El arbitraje no es un service contratado para atender un tema específico. La función arbitral es noble porque está dominada por un interés público y no por un afán privado.

De lo anteriormente expuesto, desciende inconcusamente que en la institución del arbitraje lo principal es el árbitro, su imparcialidad, independencia, competencia e integridad ética, de ahí que para reducir el riesgo de la ocurrencia de malas prácticas arbitrales, el arbitraje debe ser institucional y los árbitros de la institución, clasificados por especialidades, designados por azar.

\section{ANÁLISIS CONSTITUCIONAL DEL ARBITRAJE}

\section{Fundamentación de naturaleza pública para una institución privada}

La armonía de la vida en sociedad es una permanente meta de la comunidad que el Estado debe promover y facilitar. Ha estado presente como objetivo común arraigado y sostenido, de antiguo, en todas las civilizaciones, lo que traduce el espíritu de respeto y el anhelo de todos hacia los derechos y libertades fundamentales y los deberes para con la sociedad. Empero, esta comunión se torna imposible de realizar debido a la naturaleza humana y las circunstancias económicas, sociales, culturales y políticas que se dan en un espacio y tiempo determinado, frente a lo cual la potestad pública de administrar justicia fracasa en su intento de mantener y conservar esa correspondencia.

Basado en la premisa esencial de todo Estado democrático y de derecho, según la cual el respeto a la dignidad de la persona humana es el fin supremo de la sociedad y el Estado, que aparece en el pórtico de la Constitución Política del Perú por ejemplo, el sistema constitucional 
en los países iberoamericanos

The need to empower arbitration as a private jurisdiction in

the ibero-american countries

cumple una función medular por el sostén que brinda para conformar una cultura integradora de la sociedad con base en un sistema axiológico plural, tolerante y de apertura, como anota Haberle, P. (2000), de donde se deduce que los medios alternativos de solución de conflictos que pasen por sistemas de decisiones privados, extra judiciales y arbitrales, constituyen el quid cultural que beneficia a la concienciación cívica respecto a la significativa función de la voluntad social de realizar la Constitución, ganando de esta manera firmeza y seguridad el propio Estado, siendo ésta entonces la mayor bondad intrínseca del arbitraje y la que mayor recelo genera en los operadores de la justicia estatal, por lo que le niega el imperium y la coertio.

En el Perú, el arbitraje es una jurisdicción excepcional por mandato constitucional, sin embargo carece de dos de los atributos de toda jurisdicción mencionados anteriormente, lo cual le resta posibilidades de que sus decisiones sean auto ejecutables. Desde aquí postulamos su empoderamiento como una auténtica jurisdicción con el goce y ejercicio de los plenos atributos y poderes. En efecto, como fórmula hetero compositiva validada constitucionalmente está dirigida a contribuir a la paz social o la normalidad en la convivencia social, mediante el logro de una composición pacífica de los conflictos intersubjetivos de intereses que actúa céleremente para restablecer el equilibrio, que es precisamente lo que busca cualquier sistema jurisdiccional.

El hecho que la misma Constitución Política peruana dote al arbitraje del carácter de jurisdicción excepcional, en mérito a su reconocimiento implícito como medio alternativo y privado de solución de conflictos, significa que es un instrumento legítimo para discernir justicia, tan legítimo como el medio procesal público. No debe ponerse el acento en que el árbitro a diferencia del juez, no es elegido por un órgano estatal, sino por personas privadas, que son las mismas partes en conflicto, sino en que el sistema de justicia arbitral ha sido designado por el pueblo constituyente como un sistema válido para resolver conflictos, por ello debe tener los mismos atributos que la justicia estatal, pues ambos sistemas son constituidos. El constituyente ha querido que, en el Perú, la administración de justicia sea pública a través del Poder Judicial y privada a través del arbitraje.
Esta característica constitucional del arbitraje en el Perú, es meridianamente clara y no da lugar a dudas ni discusión alguna, como en el caso que no se le atribuyera tal carácter y se tuviera que invocar en vía argumentativa la autonomía de la voluntad y la libertad, que admiten discución. En cambio, al ser una jurisdicción tiene autorictas, vocatio, jurisdictio, notio y cognitio, no estando de acuerdo en que la ley le niegue el imperium y la coertio para ejecutar sus laudos, pues la Constitución no se lo niega y, por tanto, la ley no puede distinguir donde la ley no distingue, más aún, la Constitución no establece la jurisdicción arbitral de acuerdo a lo que disponga la ley, sino por su propio mandato.

En definitiva, las deficiencias estructurales de la justicia estatal, caracterizada por la carestía, lentitud e inseguridad, contrasta con las ventajas de la fórmula arbitral de solucionar el conflicto restaurando y/o conservando las relaciones de comunidad, que son dañadas por el sistema jurisdiccional público, de ahí que resulte necesario empoderar al arbitraje jurisdicción para que pueda realizar plenamente su thelos que lo eleva a la categoría de jurisdicción con carácter excepcional, por tanto alternativo de la justicia pública, con personalidad propia, paralela e independiente a los módulos de justicia estatal tradicionales.

La finalidad social del arbitraje es, pues, elocuente e irrebatible, de donde se desprende su fundamento incuestionable de naturaleza pública para esta jurisdicción privada.

\section{La jurisdicción arbitral}

El concepto de jurisdicción es conocido por todos y remite a la facultad de decir o declarar -con autoridad- el derecho aplicable a un caso, esto es, a resolver el conflicto intersubjetivo de intereses. La noción primigenia no constriñe el significado a que sea necesariamente una facultad pública. El monopolio de la justicia estatal obedece al histórico ejercicio del poder que el Estado moderno hace con fines de control y dominación de la sociedad y sus miembros.

Por ello, es común que el sistema de administración de justicia de los estados sea solamente público. Algunos estados, como el Perú, reconocen en su orden constitucional que el arbitraje es una jurisdicción excepcional, es decir, una atribución excluida de la regla 
común, que es la justicia ordinaria pública, con lo cual se tiene que la justicia arbitral si bien es privada, tiene fundamento público, como es la contribución a la paz social, como lo tiene la justicia pública.

En efecto, el artículo 138 de la Constitución Política del Perú, dispone que la potestad de administrar justicia emana del pueblo y se ejerce por el Poder Judicial. Es decir, la jurisdicción originaria tiene como titular al pueblo y se ejerce por la justicia estatal (Poder Judicial) pero el artículo 139 inciso 1 de la misma Ley Fundamental establece como principio y derecho de la función jurisdiccional su unidad y exclusividad, agregando que no existe ni puede establecerse jurisdicción alguna independiente, con excepción de la militar y la arbitral. Sitúa pues en la misma categoría jurisdiccional a las tres mencionadas jurisdicciones. Ergo, frente a la misma razón, existe la misma disposición.

En el caso de Chile, su Constitución Política $(1980)^{10}$ establece en su artículo 76 algo diferente a la del Perú. Dicha norma dispone que la facultad de conocer de las causas civiles y criminales, de resolverlas y de hacer ejecutar lo juzgado, pertenece exclusivamente a los tribunales establecidos por la ley. (...)" Y en su artículo 16 establece que (...) la ley señalará los casos en que la negociación colectiva deba someterse a arbitraje obligatorio, el que corresponderá a tribunales especiales de expertos cuya organización y atribuciones se establecerán en ella. (...)"

Como se puede apreciar, en este caso no se reconoce categoría jurisdiccional al arbitraje.

En el caso de Bolivia, su Constitución Política $(2009)^{11}$ en el artículo 179 dispone que

La función judicial es única. La jurisdicción ordinaria se ejerce por el Tribunal Supremo de Justicia, los tribunales departamentales de justicia, los tribunales de sentencia y los jueces; la jurisdicción agroambiental por el Tribunal y jueces agroambientales; la jurisdicción indígena originaria campesinas se ejerce por sus propias autoridades; existirán jurisdicciones especializadas reguladas por la ley. La jurisdicción ordinaria y la jurisdicción indígena originario campesina gozarán de igual

10 Fuente: Biblioteca del Congreso Nacional de Chile/BCN, recuperado del sitio de internet: https://www.leychile.cl/ Navegar?idNorma $=242302$

11 Fuente: http://www.ftierra.org/index.php/component/ attachments/download/6 jerarquía. La justicia constitucional se ejerce por el Tribunal Constitucional Plurinacional. El Consejo de la Magistratura es parte del Órgano Judicial.

Asimismo, en su artículo 366 establece que

Todas las empresas extranjeras que realicen actividades en la cadena productiva hidro carburífera en nombre y representación del Estado estarán sometidas a la soberanía del Estado, a la dependencia de las leyes y de las autoridades del Estado. No se reconocerá en ningún caso tribunal ni jurisdicción extranjera y no podrán invocar situación excepcional alguna de arbitraje internacional, ni recurrir a reclamaciones diplomáticas.

En este caso tampoco se reconoce categoría jurisdiccional al arbitraje.

En el caso de Colombia, su Constitución Política (2009) ${ }^{12}$ señala en el artículo 116 que "La Corte Constitucional, la Corte Suprema de Justicia, el Consejo de Estado, "Comisión Nacional de Disciplina, la Fiscalía General de la Nación, los Tribunales y los Jueces, administran Justicia. También lo hace la Justicia Penal Militar. El congreso ejercerá determinadas funciones judiciales. Excepcionalmente la ley podrá atribuir función jurisdiccional en materias precisas a determinadas autoridades administrativas. Sin embargo no les será permitido adelantar la instrucción de sumarios ni juzgar delitos. Los particulares pueden ser investidos transitoriamente de la función de administrar justicia en la condición de jurados en las causas criminales, conciliadores o en la de árbitros habilitados por las partes para proferir fallos en derecho o en equidad, en los términos que determine la ley.

Aquí, hay un reconocimiento transitorio en la categoría jurisdiccional al arbitraje, declarado como una posibilidad no como una realidad existente, siempre que por ley se invista de jurisdicción al árbitro habilitado por las partes.

En el caso de Venezuela, su Constitución Política $(1999)^{13}$ en el artículo 253 señala que la potestad de administrar justicia emana de los ciudadanos y ciudadanas y se imparte en nombre de la Republica por autoridad de la ley. Corresponde a los órganos del Poder Judicial conocer de las causas y asuntos de

\footnotetext{
12 Fuente: http://www.corteconstitucional.gov.co/inicio/ Constitucion\%20politica\%20de\%20Colombia.pdf

13 Fuente: https://www.oas.org/dil/esp/constitucion_ venezuela.pdf
} 
en los países iberoamericanos

The need to empower arbitration as a private jurisdiction in

the ibero-american countries

su competencia mediante los procedimientos que determinen las leyes, y ejecutar o hacer ejecutar sus sentencias. El sistema de justicia está constituido por el Tribunal Supremo de Justicia, los demás tribunales que determine la ley, el Ministerio Público, la Defensoría Pública, los órganos de investigación penal, los o las auxiliares y funcionarios y funcionarias de justicia, el sistema penitenciario, los medios alternativos de justicia, los ciudadanos o ciudadanas que participan en la administración de justicia conforme a la ley y los abogados autorizados o abogadas autorizadas para el ejercicio. Y en su artículo 258 dispone que “(...) la ley promoverá el arbitraje, la conciliación, la mediación y cualesquiera otros medios alternativos para la solución de conflictos."

En este caso, la norma constitucional prevé como parte del sistema jurisdiccional a los medios alternativos de justicia que la ley debe promover, por lo que el arbitraje forma parte de la categoría jurisdiccional.

En el caso del Ecuador, su Constitución Política (2008) ${ }^{14}$ en el artículo 167 señala que "La potestad de administrar justicia emana del pueblo y se ejerce por los órganos de la Función Judicial y por los demás órganos y funciones establecidos en la Constitución." El artículo 190 señala que "Se reconoce al arbitraje, la mediación y otros procedimientos alternativos para la solución de conflictos. Estos procedimientos se aplicarán con sujeción a la ley, en materias en las que por su naturaleza se pueda transigir (...)".

En este caso no se reconoce al arbitraje como jurisdicción.

En el caso de Guatemala, su Constitución Política (1986) ${ }^{15}$ señala en el artículo 203 que “(...) La función jurisdiccional se ejerce, con exclusividad absoluta, por la Corte Suprema de Justicia y por los demás tribunales que la ley establezca". Y el artículo 219 reconoce a los Tribunales militares; y el artículo 220 hace lo propio con los Tribunales de Cuentas.

Por tanto, la jurisdicción arbitral no está reconocida como tal.

14 Fuente: https://www.oas.org/juridico/pdfs/mesicic4_ecu_ const.pdf

15 Fuente: https://www.oas.org/juridico/mla/sp/gtm/sp_ gtm-int-text-const.pdf
En el caso de Paraguay su Constitución Política (1992) ${ }^{16}$ señala en el artículo 247 que "la administración de justicia está a cargo del Poder Judicial, ejercido por la Corte Suprema de Justicia, por los tribunales y por los juzgados, en la forma que establezcan esta Constitución y la ley." Subraya en el artículo 248 que "Queda garantizada la independencia del Poder Judicial. Sólo éste puede conocer y decidir en actos de carácter contencioso (...) sin perjuicio de las decisiones arbitrales en el ámbito del derecho privado, con las modalidades que la ley determine para asegurar el derecho de defensa y las soluciones equitativas".

Aquí no hay un reconocimiento expreso de la jurisdicción arbitral, sin embargo la norma constitucional le otorga validez y legitimidad de acuerdo a la ley a las decisiones arbitrales, en lo que calificamos como una decisión oblicua de reconocimiento sesgado.

En el caso de Argentina, su Constitución $(1994)^{17}$ señala en el artículo 108 que "El Poder Judicial de la Nación será ejercido por una Corte Suprema de Justicia, y por los demás tribunales inferiores que el Congreso estableciere en el territorio de la Nación"; y en el artículo 14 BIS dispone que “(...) Queda garantizado a los gremios: concertar convenios colectivos de trabajo; recurrir a la conciliación y al arbitraje; el derecho de huelga. (...)"

En este caso no se reconoce al arbitraje como jurisdicción.

En la Constitución Política de Brasil (1988) ${ }^{18}$, el artículo 125 señala que

Los Estados organizarán su justicia, observando los principios establecidos en esta Constitución, que son los siguientes:

1. La competencia de los Tribunales será definida en la Constitución del estado, siendo la ley de

\footnotetext{
16 Fuente: https://www.oas.org/juridico/spanish/par_res3. htm

17 Fuente: Ministerio de Justicia y Derechos Humanos de la Presidencia de la Nación, recuperado del sitio de internet: http://www.saij.gob.ar/nacional-constitucionnacional-constitucion-nacion-argentina-lns00026651994-08-22/123456789-0abc-defg-g56-62000scanyel? $\& \mathrm{o}=0 \& \mathrm{f}=\mathrm{Total} \% 7 \mathrm{CFecha} \% 7 \mathrm{CEstado} \% 20 \mathrm{de} \% 20 \mathrm{Vigencia} /$ Vigente $\% 2$ C $\% 20$ de $\% 20$ alcance $\% 20$ general $\%$ 7CTema $\% 5 B 5$ $\% 2 \mathrm{C} 1 \% 5 \mathrm{D} \% 7 \mathrm{COrganismo} \% 5 \mathrm{~B} 5 \% 2 \mathrm{C} 1 \% 5 \mathrm{D} \% 7 \mathrm{CAutor} \% 5 \mathrm{~B} 5$ $\% 2 \mathrm{C} 1 \% 5 \mathrm{D} \% 7 \mathrm{CJurisdicci} \% \mathrm{~F} 3 \mathrm{n} /$ Nacional\%7CTribunal\%5B 5\%2C1\%5D\%7CPublicaci\%F3n\%5B5\%2C1\%5D\%7CColecc i\%F3n\%20tem\%E1tica\%5B5\%2C1\%5D\%7CTipo\%20de $\% 20$ Documento/Legislaci\%F3n/Ley/Constituci\%F3n\&t=1

18 Fuente: http://www.wipo.int/edocs/lexdocs/laws/es/br/ br117es.pdf
} 
organización judicial iniciativa del Tribunal de justicia.

2. Cabe a los Estados la invocación de la inconstitucionalidad de leyes a actos normativos estatales o municipales frente a la Constitución del Estado, prohibiéndose la atribución de la legitimación para accionar a un órgano único.

3. La ley estatal podrá cerrar, mediante propuesta del Tribunal de justicia, la Justicia militar estatal, constituida, en primera instancia, por los consejos de Justicia y, en segundo lugar, por el propio Tribunal de Justicia, o por el Tribunal de justicia Militar en los Estados en que el efectivo de la Policía militar sea superior a veinte mil miembros.

4. Es competencia de la Justicia Militar estatal procesar y juzgar a los policías militares y bomberos militares en los delitos militares, definidos en la ley, pudiendo el Tribunal competente decidir sobre la pérdida de puesto y de la patente de los oficiales y de la graduación de las plazas.

Como se puede apreciar, no se hace referencia al arbitraje.

En el caso de España, su Constitución (1978) ${ }^{19}$ señala en el artículo 117 inciso 3 que "el ejercicio de la potestad jurisdiccional en todo tipo de procesos, juzgando y haciendo ejecutar lo juzgado, corresponde exclusivamente a los Juzgados y Tribunales determinados por las leyes, según las normas de competencia y procedimiento que las mismas establezcan." En el artículo 125 señala que "Los ciudadanos podrán ejercer la acción popular y participar en la Administración de Justicia mediante la institución del Jurado, en la forma y con respecto a aquellos procesos penales que la ley determine, así como en los Tribunales consuetudinarios y tradicionales."

Aquí tampoco hay un reconocimiento del arbitraje como jurisdicción.

Ahora bien, por qué razón de una muestra de diez estados latinoamericanos y uno europeo, solo uno -el Perú- reconoce expresa y categóricamente como una jurisdicción excepcional al arbitraje; otro -Venezuelaconforma su sistema de justicia con los medios alternativos de resolución de conflictos, esto

19 Fuente: Ministerio de la Presidencia y para las Administraciones Territoriales, recuperado del sitio de internet: https://www.boe.es/buscar/act. php?id=BOE-A-1978-31229 podría entenderse como un reconocimiento de jurisdicción privada, sin embargo, obsta para ello el hecho de que la conciliación y la negociación son auto compositivas, por lo que nadie declara el derecho; y en la mediación interviene un tercero pero no como decisor sino como facilitador, por lo que tampoco nadie declara el derecho. En tal sentido, interpretamos que reconocen a los medios alternativos de resolución de conflictos, el arbitraje entre ellos, y las decisiones a las que se llegue a través de ellos, como expresiones conformantes del sistema de justicia, pero no como jurisdicciones, al igual que en el tercer país -Ecuador- que también reconoce dichos medios alternativos, mas no como jurisdicción.

Un cuarto país -Paraguay- tampoco reconoce una jurisdicción arbitral pero sí reconoce la validez de las decisiones arbitrales, reservando la jurisdicción para los tribunales ordinarios. Un quinto país -Colombia- opta por la posibilidad de reconocer transitoriamente al arbitraje como jurisdicción, siempre y cuando la ley confiera jurisdicción al árbitro habilitado por las partes. No es, pues, una realidad tal reconocimiento, tan solo una posibilidad provisional.

En todos los demás casos, no hay referencia expresa al arbitraje como jurisdicción ni como medio alternativo de solución de conflictos.

La respuesta no es otra que aun en las democracias, el estado cede a su vocación hegemónica y omnipotente que torna muy difícil el reconocimiento de la jurisdicción arbitral como par de la justicia estatal; y si ello se logra dar en la letra de la Constitución Política, como ha sido explícita y manifiestamente en el caso del Perú, la ley de arbitraje desnaturaliza dicho reconocimiento mediatizando las potestades de la jurisdicción obligando al árbitro a acudir al Poder Judicial para asegurar el cumplimiento de sus decisiones en el proceso y sus laudos, con lo cual en la práctica la subordina ante la jurisdicción pública y demuestra que no hay una franca apertura democrática para cumplir con la finalidad de resolver conflictos y restablecer la armonía social.

$\mathrm{Y}$ es que el paradigma del principio democrático de la separación de funciones del estado, nos inclina a pensar arquetípicamente que toda función jurisdiccional es judicial. Pero no es así. Una función judicial es la que asume el Poder Judicial, que conoce de 
en los países iberoamericanos

The need to empower arbitration as a private jurisdiction in

the ibero-american countries

juicios o procesos judiciales. En cambio, una función jurisdiccional es, como se ha dicho, la que conoce de un conflicto, declara el derecho para solucionar dicho conflicto $y$ exige el cumplimiento de lo resuelto. No debe haber confusión. Lamentablemente, existe la tendencia a confundir ambas funciones en beneficio del ámbito judicial y en desmedro de la función jurisdiccional arbitral, en línea con la tendencia hegemónica y la capacidad monopolizadora estatal. Por eso, hacen bien las constituciones políticas que han decidido establecer una jurisdicción arbitral independiente de la jurisdicción común, sin embargo, hacen mal las leyes generales de arbitraje que distinguen materias y desconocen el imperium y la coertio que las constituciones políticas no le niegan al arbitraje.

En ambas jurisdicciones, además, interviene un tercero imparcial para declarar el derecho, aplicar la norma al caso concreto y exigir su cumplimiento coactivamente, con la finalidad de satisfacer el agravio al derecho de la parte lesionada y de restablecer la armonía social, de lo contrario no se cumpliría el thelos de la función -pública o privada- de resolver los conflictos. Si dichos terceros decisores son jueces (iudex), esto es, personas que tienen autoridad (constitucional) para conocer, decir o declarar el derecho para resolver conflictos, entonces es natural que tengan también la potestad de hacer cumplido lo que resuelven, de lo contrario se les debilitaría y esterilizaría funcionalmente.

Según Casco, H. (2000) los elementos de la jurisdicción reconocidos generalmente son la notio, que es el derecho de conocer una cuestión determinada; la vocatio, que es la facultad de obligar a las partes a comparecer; la coertio, que es la facultad de recurrir a la fuerza para lograr el cumplimiento de las medidas dentro del proceso; la judicium, que es la facultad de dictar sentencia poniendo término a la litis; y el imperium, que es el poder para ejecutar las resoluciones judiciales, mediante el auxilio de la fuerza pública.

Si revisamos la institución del arbitraje, con miras a sostener que es una jurisdicción, se advierte que el árbitro unipersonal o tribunal arbitral tiene la notio, esto es, el derecho de conocer sobre un conflicto determinado, dado que las partes así lo han pactado libre y voluntariamente en una cláusula arbitral, y a veces por el mérito de alguna disposición normativa como son los artículos 62 y 63 de la Constitución Política, según los cuales los conflictos surgidos de una relación contractual solo se solucionan en la vía arbitral o en la judicial; y que el estado y las personas de derecho público pueden someter las controversias derivadas de la relación contractual a arbitraje nacional, respectivamente.

También posee vocatio, pues existe la obligación de las partes de cumplir un laudo contrario a sus intereses. Más aún, la jurisdicción ordinaria permite una excepción de convenio arbitral.

Asimismo, ostenta judicium desde que la finalidad de la jurisdicción arbitral es resolver un conflicto y, por ello, lo que juzgó y decidió adquiere estado y firmeza.

Sin embargo, la ley no le reconoce coertio, pues no puede el árbitro recurrir a la fuerza para asegurar el cumplimiento de las decisiones dentro del proceso; tampoco le acuerda imperium, pues el árbitro requiere del auxilio del juez común para que su laudo sea ejecutado, no puede dirigirse directamente al órgano de la fuerza pública.

Entonces, si un juez no puede ejecutar coactivamente sus resoluciones; y si tampoco puede recurrir a la fuerza pública para que se cumplan las medidas que decide dentro del proceso que conoce, carece de imperium y de coertio. Ergo ¿qué clase de juez es? No puede haber un juez a medias porque el estado democrático y de derecho que contempla su existencia resultaría afectado.

No es democrático abrazar el paradigma de que el estado es el único, exclusivo y excluyente abastecedor y distribuidor del servicio de justicia. Esta idea corresponde a un modelo estatista, contrario a la autonomía de la voluntad de los ciudadanos $\mathrm{y}$, por ende, a la democracia como forma de organización política de la sociedad. Nuevamente ¿por qué un laudo necesita de la intervención del Poder Judicial en caso de incumplimiento de una de las partes, para ser ejecutado?

¡Cuidado! En el caso peruano, la Constitución Política en su artículo 139 inciso 2 establece que ninguna autoridad puede interferir en el ejercicio de las funciones de un órgano jurisdiccional, ni modificar sentencias ni 
retardar su ejecución. Se observa aquí un verdadero galimatías jurídico, pues no tendría que intervenir ningún juez estatal para ejecutar lo decidido por un juez privado (árbitro).

\section{Problemas actuales del arbitraje}

\subsection{El control judicial posterior}

Un primer problema de los que confronta la jurisdicción arbitral, que deseamos abordar, es el relativo al control judicial posterior por parte de la justicia estatal. En efecto, el Decreto Legislativo $\mathrm{N}^{\circ} 1071^{20}$ norma el arbitraje en el Perú y en su artículo 3 establece como principios y derechos de la función arbitral la independencia, en virtud de la cual no depende de nadie sino de sí misma y goza de libertad. Tal y conforme se dice de la justicia estatal, lo cual corresponde a toda jurisdicción desde la aparición del estado moderno.

Sin embargo, el mismo artículo señala en el inciso 4 que ninguna actuación ni mandato fuera de las actuaciones arbitrales podrá dejar sin efecto las decisiones del tribunal arbitral, a excepción del control judicial posterior mediante el recurso de anulación del laudo contemplado en este Decreto Legislativo. Cualquier intervención judicial distinta, dirigida a ejercer un control de las funciones de los árbitros o a interferir en las actuaciones arbitrales antes del laudo, está sujeta a responsabilidad.

El análisis crítico que nos merece esta disposición es que constituye un verdadero problema, por cuanto la jurisdicción arbitral reconocida constitucionalmente se encuentra, en nuestra opinión, en el mismo nivel jurisdiccional que la justicia estatal, por ende no existe razón para justificar un recurso de anulación, salvo que en el proceso arbitral o en el laudo se advierta la violación de algún derecho fundamental, en cuyo caso si se justifica la intervención de un juez estatal, máxime si generalmente la cláusula arbitral no contempla la doble instancia, la cual considero que debiera existir obligatoriamente, pues siendo una jurisdicción debe cumplir con todos los principios y garantías de la función jurisdiccional.

20 Fuente: Diario Oficial El Peruano. Recuperado del sitio de Internet: http://www.pcm.gob.pe/InformacionGral/ogaj/ archivos/DL-1071.pdf
Si existiera la doble instancia, sería la segunda instancia a la que debería recurrirse en ese extremo, en vía de apelación, a fin de permanecer en la jurisdicción arbitral y hacer realidad su plena independencia. Esta alternativa de solución se corresponde con lo que dispone el artículo 8 inciso 4 del mencionado decreto legislativo, el cual señala la competencia de la Sala Civil Subespecializada en lo Comercial o, en su defecto, la Sala Civil de la Corte Superior de Justicia del lugar del arbitraje, para conocer del recurso de anulación del laudo, es decir, no un juez de la justicia estatal sino su instancia superior, que guarda equivalencia jerárquica con una segunda instancia arbitral.

Entonces, la jurisdicción arbitral constitucionalmente reconocida $i$ es verdadera y plenamente independiente? ¿O está sometida a la jurisdicción estatal?

No haber previsto esta circunstancia permite que el arbitraje se siga considerando como un proceso alternativo de solución de conflictos y no como un proceso jurisdiccional, que es su verdadera naturaleza, el cual propende a un fin social que es contribuir a alcanzar la paz social a través de una administración de justicia privada.

\subsection{La ejecución forzosa de lo decidido por el tribunal arbitral}

Este es un segundo problema que confronta el arbitraje como jurisdicción, al carecer de imperium y de coertio.

En cuanto a las medidas cautelares y su ejecución, el artículo 48 de la ley bajo comento señala que el tribunal arbitral está facultado para ejecutar, a pedido de parte, sus medidas cautelares, salvo que, a su sola discreción, considere necesario o conveniente requerir la asistencia de la fuerza pública. En los casos de incumplimiento de la medida cautelar o cuando se requiera de ejecución judicial, la parte interesada recurrirá a la autoridad judicial competente, quien por el solo mérito de las copias del documento que acredite la existencia del arbitraje y de la decisión cautelar, procederá a ejecutar la medida sin admitir recursos ni oposición alguna. La autoridad judicial no tiene competencia para interpretar el contenido ni los alcances de la medida cautelar. Cualquier solicitud de aclaración o precisión sobre los mismos o sobre la ejecución cautelar, será solicitada por 
en los países iberoamericanos

The need to empower arbitration as a private jurisdiction in

the ibero-american countries

la autoridad judicial o por las partes al tribunal arbitral. Ejecutada la medida, la autoridad judicial informará al tribunal arbitral y remitirá copia certificada de los actuados.

Como se puede apreciar, el tribunal arbitral está autorizado para ejecutar las medidas cautelares que dicte en el proceso, salvo que considere necesario o conveniente requerir el auxilio de la fuerza pública. Esta salvedad es una adición cosmética destinada a salvar el honor del tribunal arbitral, pues mejor hubiera sido que la norma declarara, como lo hace para la justicia estatal, que la autoridad jurisdiccional ejecuta sus propios mandatos pudiendo solicitar el auxilio de la fuerza pública, expresión que es esencialmente diferente.

En cuanto a la ejecución del laudo, el artículo 59 de la ley sub examen indica que si la parte obligada no cumple con lo ordenado por el laudo, en la forma y en los plazos establecidos, o en su defecto, dentro de los quince (15) días de notificada con el laudo o con las rectificaciones, interpretaciones, integraciones y exclusiones del laudo, cuando corresponda; la parte interesada podrá pedir la ejecución del laudo a la autoridad judicial competente, salvo que resulte aplicable el artículo 67, referido a la ejecución arbitral.

Según el artículo 67, a solicitud de parte, el tribunal arbitral está facultado para ejecutar sus laudos y decisiones, siempre que medie acuerdo de las partes o se encuentre previsto en el reglamento arbitral aplicable. Se exceptúa de lo dispuesto en el numeral anterior, el caso en el cual, a su sola discreción, el tribunal arbitral considere necesario o conveniente requerir la asistencia de la fuerza pública. En este caso, cesará en sus funciones sin incurrir en responsabilidad y entregará a la parte interesada, a costo de ésta, copia de los actuados correspondientes para que recurra a la autoridad judicial competente a efectos de la ejecución.

Peor aún, el artículo 68 señala sobre la ejecución judicial que la parte interesada podrá solicitar la ejecución del laudo ante la autoridad judicial competente acompañando copia de éste y de sus rectificaciones, interpretaciones, integraciones y exclusiones y, en su caso, de las actuaciones de ejecución efectuada por el tribunal arbitral. La autoridad judicial, por el solo mérito de los documentos referidos en el numeral anterior, dictará mandato de ejecución para que la parte ejecutada cumpla con su obligación dentro de un plazo de cinco (5) días, bajo apercibimiento de ejecución forzada. La autoridad judicial está prohibida, bajo responsabilidad, de admitir recursos que entorpezcan la ejecución del laudo.

Decimos peor aún porque si el artículo 67 trasunta la posibilidad de que el propio tribunal arbitral desmaye en la ejecución del laudo, este artículo 68 a continuación socava la facultad del tribunal arbitral al otorgar a la parte interesada el derecho de solicitar la ejecución ante la autoridad judicial. En otras palabras, ni cree en que el tribunal arbitral deba ejecutar sus propias decisiones ni deja a las partes creer en ello.

Significa entonces que, en realidad, el tribunal arbitral no está facultado con suficiente fuerza ni creencia, para ejecutar su laudo. Tiene que hacerlo la autoridad judicial competente (que según la ley es el juez sub especializado en lo comercial o, en su defecto, el juez civil del lugar del arbitraje o el del lugar donde el laudo debe producir su eficacia). Solo el tribunal arbitral puede ejecutar sus laudos si las partes así lo han acordado o se encuentra previsto en el reglamento arbitral. Empero, el propio tribunal arbitral puede requerir el auxilio de la fuerza pública, en cuyo caso se auto elimina por mandato de la ley, esto es, cesa en sus funciones y la parte interesada deberá recurrir a la autoridad judicial competente para que ejecute el laudo.

Esta circunstancia legislada recuerda algunos casos del reino animal, por la práctica de la antropofagia de la jurisdicción estatal respecto de la arbitral debida al dimorfismo de ambas jurisdicciones, como en el caso de algunos arácnidos, como la viuda negra; el caso de los lophiiformes peces de las profundidades, cuyas hembras de gran tamaño convierten a los machos en parásitos que se "fusionan" con ellas, pues morirían de no encontrar una pareja, siendo que aquí las jurisdicciones estatal y arbitral se fusionan para que la jurisdicción arbitral "muera" y la estatal ejecute "post mortem" lo decidido por aquella; el caso de la mantis religiosa, que cuando el macho comienza a introducir su semen en el abdomen de la hembra, ésta rápidamente devora la cabeza del macho, sin detener el proceso reproductivo, lo que ocurre al devorar la jurisdicción estatal a la arbitral cuando ésta deposita en su seno su producto final; y el caso de las abejas machos 
denominados "zánganos", que se desarrollan aparte del resto de la colmena y su único propósito es fecundar a la reina, siendo que mueren una vez que procrean, como ocurre con la justicia arbitral para ejecutar su laudo recurre a la justicia estatal y cesa en sus funciones.

Metáforas aparte, la situación se torna peor todavía, cuando se norma simultáneamente que la parte interesada puede menospreciar y humillar al tribunal arbitral prefiriendo dirigirse a la autoridad judicial para solicitar la ejecución. No he visto peor manera de desfigurar una norma y una categoría constitucional (me refiero a la jurisdicción arbitral reconocida por la Constitución Política del Perú).

En verdad no se llega a comprender por qué razón la norma describe un sinuoso y farragoso sendero diciendo que el tribunal arbitral está facultado para ejecutar pero puede decidir solicitar el auxilio de la fuerza pública, pero si lo hace cesa en sus funciones y la ejecución pasa a la justicia estatal. Otro galimatías jurídico. Se advierte, de un lado, una indefinición normativa caótica y, por otro lado, una indecisión mayúscula de política jurisdiccional que acusa una grave ausencia de identidad que afecta a la jurisdicción arbitral.

¿Cómo puede la jurisdicción arbitral brindar tutelajurisdiccional, que es otro de los principios y garantías de la función jurisdiccional, si no puede por sí misma ejecutar sus decisiones? Nuevamente el juego de la óptica estatal, hacer creer a la población que necesita de la jurisdicción estatal para hacer justicia, cuando en realidad toda jurisdicción, incluida la estatal, solo necesita de la colaboración del Poder Ejecutivo que le sea requerida en los procesos, porque de él dependen los órganos coactivos, como la policía nacional. Igual el tribunal arbitral podría dirigirse a la policía nacional para que le preste el auxilio de la fuerza pública en caso sea menester para ejecutar sus decisiones.

Frente a este laberinto normativo que revela una falta de compromiso del ordenamiento jurídico con el reconocimiento constitucional de la jurisdicción arbitral, la ley en mención proclama que todo laudo es definitivo, inapelable y de obligatorio cumplimiento desde su notificación a las partes, lo cual no pasa de ser una ironía inaceptable por las fisuras que han sido anotadas anteriormente para cada caso.
Entonces, la jurisdicción arbitral constitucionalmente reconocida iostenta los atributos de imperium y de coertio que exhibe toda jurisdicción? ¿Existe razón para que sea una jurisdicción mutilada y disminuida si tiene el mismo fin que la jurisdicción estatal? ¿No es este cercenamiento una manifestación de la vocación hegemónica y monopólica de la jurisdicción estatal?

\subsection{La doble instancia en el proceso arbitral}

Es el tercero de los problemas que hemos seleccionado para analizar. El arbitraje en el Perú es una jurisdicción constitucional. Sin embargo, hemos visto cómo la ley que regula el arbitraje desnaturaliza y trasgrede la Constitución Política al someter la jurisdicción arbitral a la jurisdicción estatal, llamando eufemísticamente colaboración y asistencia judicial a este sometimiento, el cual se da porque la ley le niega, cuando la Constitución no lo hace, los atributos jurisdiccionales de imperium y de coertio, de los que goza toda jurisdicción.

¿Por qué razón se produce este avasallamiento del Estado en perjuicio de la jurisdicción arbitral reconocida constitucionalmente sin limitación alguna? Sostenemos que es por la misma razón por la cual el estado moderno, desde su aparición en el siglo XIII, año 1215 aproximadamente, confisca el conflicto a la población y monopoliza la administración de justicia, entonces a través de jueces dependientes del monarca, hoy a través de jueces formalmente independientes pero de una u otra manera sometidos al poder político o económico, que conforman una élite o casta de profesionales togados que, al igual que la clase política en el poder, han perdido la idea de por qué están donde están, esto es, de que son mandatarios y ejercen un poder que les ha sido delegado por el pueblo, el que es el titular del poder y del poder de administrar justicia.

En esa línea, como la administración de justicia es una forma de ejercer control social formal, el estado no desea competencia alguna en esa área, aunque provenga del propio pueblo a través de la designación voluntaria y directa de profesionales no togados, expertos y altamente calificados para resolver conflictos. El estado no quiere que la jurisdicción arbitral evolucione, desarrolle y se haga más fuerte y extendida, por eso retiene en su perjuicio las facultades 
en los países iberoamericanos

The need to empower arbitration as a private jurisdiction in

the ibero-american countries

de imperium y de coertio. Si la potestad de administrar justicia emana del pueblo y si el estado ha reconocido consecuentemente la existencia de la jurisdicción arbitral en la misma Constitución Política ¿por qué al regular ésta en la ley inferior le mutila dos facultades esenciales? Pues precisamente para que las partes que han preferido acudir a la jurisdicción arbitral se vean obligados a recurrir a la jurisdicción estatal para ejecutar las decisiones de aquella, con lo cual logra que se le reconozca públicamente como endeble y que se le identifique meramente como un medio alternativo de solución de conflictos, pero con el auxilio final del Poder Judicial.

Las características positivas y beneficiosas de la jurisdicción arbitral, fundamentalmente vinculadas a la voluntariedad, que le da nacimiento y por tanto tiene el efecto de generar una conciencia y un compromiso real sobre el deseo de solucionar un conflicto de intereses; la libertad de las partes para acordar las normas que habrán de regir en un proceso, lo cual le da una característica de flexibilidad más acorde a la realidad que los procedimientos judiciales rituales y excesivamente formales; la celeridad y oportunidad, que en un escenario de conflicto son valiosas para el análisis costo-beneficio; la especialización del órgano decisorio, que es mayor y mejor que el órgano de justicia estatal, más caracterizado por la rutina y la burocracia; y la menor posibilidad de corruptibilidad, pues de la acendrada actuación individual de los árbitros dependerá su futuro profesional como tales, por su carácter privado, a diferencia del juez estatal que es todavía lejano al control real y efectivo por las marañas y espesuras del sistema; hacen inevitable la comparación con el funcionamiento de la jurisdicción estatal, por lo que ésta opta por mantener a la jurisdicción arbitral como subordinada, contra el nivel que le reconoce la Constitución Política.

En cambio, este panorama podría atenuarse si es que se dota a la jurisdicción arbitral de la doble instancia, pues ello configuraría una especie de organicidad y sistematicidad mayor a la que actualmente tiene, de suerte que otro tribunal arbitral revise en vía de apelación lo decidido por el anterior, pudiendo hacerse por taxativas causales, al igual que se hace actualmente con la posibilidad de pedir la anulación del laudo ante la justicia estatal. El hecho de que se haya optado por llevar a cabo esta posibilidad ante la justicia estatal y no ante a justicia arbitral, denota una vez más el paradigma de hegemonía de ésta sobre aquella, que no tiene sentido ni razón de ser por constituir ambas iguales jurisdicciones. Mejor sería que esa posibilidad se pueda materializar, si fuere el caso, ante el mismo seno de la jurisdicción arbitral, ante otro tribunal arbitral, previsto en el convenio arbitral si las partes así lo desearen.

Esta doble instancia permitiría, además, cumplir con la argumentación que venimos utilizando para sostener nuestra tesis de que es necesario empoderar la jurisdicción arbitral en esta región. Nuestra línea argumentativa de que la jurisdicción arbitral es una jurisdicción constitucional de igual nivel jerárquico a la estatal y, por tanto, no debería tener que acudir a ésta para que sus decisiones sean ejecutables, permite sostener válidamente que debería tener los mismos principios y garantías que establece el artículo 139 de la Constitución Política del Perú para toda función jurisdiccional, siendo uno de ellos el de la instancia plural.

La superación de estos tres problemas analizados permitirá afianzar la jurisdicción arbitral y extenderla con toda seguridad al ámbito de las personas naturales, pues su acción positiva se centra actualmente en las personas jurídicas, razón por la cual no es muy conocida por la población su existencia, reconocimiento jurisdiccional y posibilidad de empleo para dirimir conflictos con prontitud y seguridad jurídica, lo cual forma parte de la necesidad de empoderamiento que postulamos aquí.

\section{ELOGIO DEL ARBITRAJE}

Lo que asevera Brandt (2013, pág. 133) y que gloso a continuación, es pertinente tenerlo en cuenta para la tesis de empoderamiento del arbitraje latinoamericano que postulo en el presente artículo:

En un Estado democrático el ciudadano no debería ser solo el objeto de la justicia sino también su sujeto. En el concepto ideal, el juez lego es representante del pueblo, que vigila el cumplimiento del debido proceso y es un garante de los principios de la oralidad y publicidad. Los jueces ciudadanos son los llamados a introducir en las deliberaciones de los tribunales los valores principales que rigen a la población y promover procedimientos transparentes y entendibles. De esta manera se quiere reforzar la confianza de la población en dicha institución. 
En efecto, el arbitraje permite democratizar la justicia mediante la participación de la población al designar a sus propios jueces ciudadanos (árbitros) para que resuelvan su conflicto, superando el centralismo judicial, cambiando el idioma extremadamente enrevesado y forense por uno sencillo y cotidiano, permitiendo que la población comprometida desde la designación de los árbitros comprenda mejor los motivos de la decisión adoptada. Hay, evidentemente, una disminución de la fisura existente entre la práctica judicial y la realidad social cotidiana.

La principal ventaja de empoderar a la jurisdicción arbitral es la de disminuir la crisis de legitimidad de la que padece actualmente la jurisdicción estatal, pues los ciudadanos pueden controlar el amplio poder que tienen los jueces profesionales, pues las decisiones judiciales no solo afectan a las partes en conflicto, sino tienen directamente que ver con la vida institucional de nuestra sociedad.

Está fuera de discusión que el arbitraje es una gran herramienta. Ha servido para canalizar y resolver problemas sociales serios en todo el mundo, como refiere Gonzáles de Cossío, Francisco ${ }^{21}$. Dicha herramienta está debilitada

$21 \mathrm{El}$ Claims Resolution Tribunal for Dormant Accounts in Switzerland creado para ventilar las reclamaciones sobre titularidad de las 'cuentas durmientes' en Suiza por los herederos de las víctimas del Holocausto que hayan depositado dinero y otros valores en bancos suizos, mismo que puso fin a un problema que tomó más de medio siglo resolver.

Las comisiones ad hoc establecidas entre la República de Etiopía y el Estado de Eritrea para poner fin a la disputa territorial entre dichos países y para arbitrar las reclamaciones que resultaron de las violaciones al derecho internacional humanitario.

El arbitraje de inversión que despolitiza controversias entre inversionistas extranjeros y Estados anfitriones de inversiones, evitando incidentes bélicos.

El arbitraje deportivo, que ha servido como foro para dirimir eficientemente controversias en ese ámbito.

El arbitraje de comercio internacional, gracias al cual en la actualidad se ha procurado un Estado de Derecho del comercio internacional nunca antes presenciado.

La Comisión de Bosnia y Herzegovina establecida mediante el Dayton Peace Agreement que puso fin a la Guerra de los Balcanes entre Bosnia y Herzegovina y que busca ventilar $\mathrm{y}$ resolver las reclamaciones por bienes inmuebles cuya enajenación no fue voluntaria.

Es probable que se generen comisiones que ventilen y resuelvan reclamaciones derivadas de los conflictos humanitarios en Rwanda, Sierra Leone y Congo.

Importantes obras de infraestructura, dentro de las cuales resalta por su importancia las disputas derivadas del Túnel entre Francia y Reino Unido, mismas que fueron ventiladas mediante arbitraje ante la Corte Permanente de Arbitraje de La Haya. El Tribunal Arbitral la calificó como la obra financiada en forma privada más grande de la historia.

Información disponible en: http: / / www.gdca.com.mx/PDF/ arbitraje/Arbitraje $\% 20$ Evaluado\%20Rev\%20Econ $\% 20 y \% 20$ Der\%20Peru.pdf en el Perú y los países iberoamericanos Hay que empoderar al arbitraje como jurisdicción $\mathrm{y}$ otorgarle todos los atributos que una jurisdicción posee, fundamentalmente el imperium y la coertio de los que actualmente carece.

Lalistadeventajasdiferencialesdelajurisdicción arbitral con relación a la jurisdicción estatal, se inicia con la democratización de la manera de resolver los conflictos con la intervención de un tercero privado, lo cual apunta a la construcción de una cultura de paz social, ante el descrédito, inoperatividad e ineficacia de la justicia estatal; y continúa con la conciencia y el compromiso de las partes expresado en la voluntad de someterse al proceso arbitral, designando árbitros y eligiendo las reglas, lo cual asegura en mejor medida el acatamiento y respeto a lo decidido; el sentido de oportunidad en mérito a su celeridad y flexibilidad de formas procedimentales como expresión de la voluntad de las partes; su alta especialización derivada de la competencia y experiencia de los árbitros elegidos; y su menor riesgo de corrupción al no depender del sistema estatal sino de su propia labor profesional que le da imagen y prestigio.

Cualquier enaltecimiento del arbitraje no puede concluir sin hacer explícita referencia a la señera figura de William Randal Cremer ${ }^{22}$ (1828-1908), destacado representante del movimiento obrero inglés, pacifista y miembro del parlamento inglés, ganador del Premio Nobel de la Paz de 1903, quien participó en la creación de la Working men>s Peace Association (Asociación de Trabajadores por la Paz), la que tenía la firme voluntad de promover la creación de un organismo internacional de arbitraje; postuló en las elecciones de 1868 enarbolando la idea de crear una instancia internacional de arbitraje para evitar los conflictos armados; inició en 1887 las conversaciones con el fin de llegar a un tratado de arbitraje entre los Estados Unidos de América y la Gran Bretaña, logrando concienciar a las personas; originó con su idea sobre el arbitraje la Conferencia Interparlamentaria para el arbitraje, que en 1899 se convirtió en la Unión Interparlamentaria; y recibió en 1903, por su trabajo en el arbitraje internacional y por el

22 Nobel Prizes and Laureates en Nobelprize.org The official web site of the Nobel Prize. Disponible en https://www. nobelprize.org/nobel_prizes / peace/laureates / 1903/
cremer-bio.html 
en los países iberoamericanos

The need to empower arbitration as a private jurisdiction in

the ibero-american countries

pacto anglo-americano, el Premio Nobel de la Paz, cuyo importe donó a la Liga Internacional de Arbitraje.

Su evocación es elocuente demostración de una consideración encomiable del arbitraje, que por sus indiscutibles méritos se ha encumbrado, en el caso del Perú, a nivel de jurisdicción, según la normativa constitucional $\mathrm{y}$, en el caso de otros países, es considerado un excelente y eficaz medio alternativo de solución de conflictos.

\section{CONCLUSIONES}

El arbitraje es un medio de resolución de conflictos que precede al estado $y$, consecuentemente, es anterior a la forma vertical en que éste interviene en el conflicto suscitado entre las personas.

La voluntad de las partes de emplear el arbitraje, elegir al o los árbitros, así como acordar las reglas de procedimiento, expresan la genuina raigambre democrática de esta forma comunitaria de componer un conflicto de manera privada, sin intervención del estado, la cual supone una conciencia, un compromiso y un vínculo horizontal de lograr una solución al problema que se anticipa a la aparición del conflicto mismo.

La naturaleza del arbitraje es sui géneris, no se agota en la visión contractualista que solo marca su inicio; ni en la perspectiva jurisdiccional que no extingue la autonomía de la voluntad sino por el contrario la reconoce como una alternativa para la solución de conflictos que merece equipararse a la jurisdicción estatal; es una naturaleza autónoma, singular y distintiva.

Su antigüedad, origen democrático y probada eficacia ha permitido que algunos estados democráticos como el peruano, reconozcan en su constitución política la jurisdicción arbitral como una excepción a la jurisdicción estatal, lo que connota que tales estados se muestran de acuerdo y están conformes con dicha alternativa de solucionar los conflictos de modo diferente al de la jurisdicción pública.

Otros estados igualmente democráticos no otorgan al arbitraje un reconocimiento como jurisdicción, pero lo mencionan encogidamente como jurisdicción transitoria o temporal de ciudadanos; en otros pocos casos simplemente como un medio alternativo de resolución de conflictos, cuyos resultados encuentran válidos y respetables por los órganos de la justicia estatal; o como sucede en la mayoría de los países latinoamericanos no hacen mención alguna en sus constituciones políticas, dejando la materia para ser normada por la legislación ordinaria.

El denominador común que caracteriza la regulación del arbitraje en los estados latinoamericanos, es que depende de la jurisdicción estatal para la ejecución de lo que se decida en él, aun cuando esa dependencia se pretenda disimular con los términos de colaboración y asistencia, situación que se presenta marcadamente grave cuando le ha sido reconocido constitucionalmente el nivel de jurisdicción arbitral, pues esta categoría le debe permitir ejercitar los poderes de toda jurisdicción, de los cuales carece de imperium y de coertio, es decir, de que sus decisiones procesales (medidas cautelares) y finales (laudos) sean en la práctica realmente auto ejecutables.

Esta dependencia se revela, asimismo, con la posibilidad de un control judicial posterior por determinadas causales que podrían conllevar la anulación del laudo, contingencia que resulta ajena a una jurisdicción, y que solo podría preverse para el caso que se violen derechos fundamentales, como ocurre con otras jurisdicciones reconocidas constitucionalmente, cuyas decisiones son irrevisables por el Poder Judicial excepto cuando se afecten derechos humanos, tal el caso de la justicia militar, la justicia electoral y la justicia disciplinaria sancionadora de la magistratura, que son ejercidas mediante organismos públicos; y de la justicia de las comunidades originarias, que cuentan con su propio órgano ejecutor.

La inexistencia de la garantía de la doble instancia, que realiza el principio de la instancia plural, característico de toda jurisdicción es, además, otro problema constitucional que confronta la jurisdicción arbitral, cuya superación permitiría vencer cualquier argumentación a favor del control judicial posterior que contribuye con la dependencia de la jurisdicción estatal, ya que en el seno mismo de la jurisdicción arbitral se revisaría el laudo, sin intervenciones extrañas proscritas por la misma Constitución Política. 
Lo más sensible de esta problemática es que se encuentra normada por ley, pese a que la Constitución Política no le recorta ningún poder a la jurisdicción arbitral, lo cual permite observar una desnaturalización y transgresión constitucional, así como colegir que la vocación hegemónica y monopolizadora del estado, no admite competitividad en la administración de justicia, no obstante que la alternativa (jurisdicción arbitral) exhibe títulos democráticos y acredita eficacia en la solución de los conflictos, contra la impronta cada vez más ilegítima de la jurisdicción estatal y su inveterada inefectividad, que agobian a la ciudadanía y la afectan con la supervivencia de los conflictos irresueltos.

La verdadera razón de esta injerencia inadmisible de una jurisdicción en otra es facilitar la conservación del paradigma histórico de la existencia del estado como una autoridad indispensable para ejercer control y dominación social intolerables, no para garantizar las decisiones de las personas como debiera ser.

La falta de desarrollo de la jurisdicción arbitral en los países latinoamericanos pone de manifiesto una política restrictiva del estado para que la ciudadanía acceda con conocimiento y plena convicción a las formas alternativas de resolución de conflictos, especialmente a la jurisdicción arbitral, las cuales aparecen en la práctica con roles secundarios, cuando están llamadas a ser las artífices en la construcción de la cultura de paz social que tanta falta hace en la región latinoamericana.

Las virtudes y bondades de la jurisdicción arbitral, que la hacen conveniente en cualquier estado latinoamericano al lado de la justicia estatal, descubren la necesidad de empoderarla para que la población tenga la posibilidad de elegir entre intentar solucionar de una manera horizontal el conflicto en el que se encuentra inmersa, recuperando las relaciones de comunidad afectadas, mediante la intervención de un tercero especializado, privado, independiente e imparcial, ajeno a las jerarquías oficiales del estado, para que decida el conflicto sin la tentación burocrática, de la rutina, la aprensión por la influencia mediática y de la opinión pública o de la corrupción.

El empoderamiento de la jurisdicción arbitral gravita en reconocerle el goce y ejercicio de todos los poderes y atributos jurisdiccionales que le corresponden por haberle sido otorgada constitucionalmente dicha calidad, en mérito a la libertad contractual y autonomía de la voluntad existentes en todo estado democrático, especialmente los poderes de imperium y coertio para que sus decisiones sean auto ejecutables; y la posibilidad de la existencia de una segunda instancia -como también corresponde a toda jurisdicciónigualmente decidida y designada por las partes, a fin de que no se admita la intervención de la jurisdicción estatal durante el proceso ni después de emitido el laudo, subsistiendo el control judicial posterior únicamente en caso de violaciones de los derechos fundamentales.

De esta manera, los países latinoamericanos podrán tener a disposición de sus poblaciones una jurisdicción privada potenciada, realmente autosuficiente, como verdadera alternativa a la jurisdicción estatal, que les permita satisfacer sus esperanzas de justicia y consolidar sobre bases comunitarias sus anhelos de paz social, superando conflictos intersubjetivos que la justicia estatal no resuelve sino agrava, al actuar el juez como un tercero que no es imparcial al decidir en función de la perpetuación de la presencia del estado, del que es funcionario, en los conflictos personales que la mayoría de las veces causa por la configuración de sus estructuras económicas, sociales, culturales y políticas; y que nunca resuelve.

\section{FUENTES DE INFORMACIÓN}

\section{Fuentes bibliográficas}

Anitúa, Gabriel Ignacio (2015) "Historias de los pensamientos criminológicos" Ediciones Didot, Buenos Aires, Argentina.

Casco Pagano, Hernán (2000) "Derecho Procesal Civil". Editora Tricolor S.R.L. Asunción.

Haberle, Peter (2000). "Teoría de la Constitución como ciencia de la cultura", Tecnos, Madrid.

Lorca Navarrete, Antonio (2001), Littigio est quod notamus in arbitratum. San Sebastián.

Merchán Álvarez, A. (1981) “El Arbitraje. Estudio histórico-jurídico”. Sevilla. 
Pavarini, Massimo (2010) “Control y dominación. Teorías criminológicas burguesas y proyecto hegemónico" XXI Siglo veintiuno editores, Buenos Aires, Argentina.

Vidal Ramírez, Fernando (2006). "Jurisdiccionalidad del arbitraje". Revista Peruana de Arbitraje 3. Lima: Grijley

\section{Fuentes hemerográficas}

Brandt, Hans-Jürgen (2013) "Participación ciudadana en la Justicia Penal: ¿Democratización o adorno inútil de los tribunales? En Revista Vox Juris, Número 26, Perú.

Lorca Navarrete, Antonio (2008). "Algunas aportaciones sobre una nueva concepción de la naturaleza jurídica del arbitraje: su ámbito negocial-procesal". Athina 5. Revista de Derecho de los Alumnos de la Universidad de Lima. Lima.

Maluquer Montes, C. (2001), "Oferta pública de sometimiento al sistema arbitral", en Estudios sobre consumo $N^{o}$ 59, Madrid.

Montaño Bedoya, Julia Victoria (2009). "Arbitraje e intervención estatal". Revista Holística Jurídica 5. Medellín: Facultad de Derecho de la Universidad de San Buenaventura, seccional Medellín.

VeraCacho, Giusseppi(2013)“Consideraciones generales acerca del arbitraje" Ius et Praxis, Revista de la Facultad de Derecho $N^{\circ} 44$, Lima, ISSN 1027-8168.

\section{Fuentes electrónicas}

Cremades, B., (2001) Consolidación de la autonomía de la voluntad en España: El arbitral, Tratado de derecho arbitral, Soto Coaguila, Ed. Colección de Estudios, Tomo I.5.Ezcurra Rivero, Huáscar (2015) “Corrupción y Arbitraje: A propósito de las Reglas IBA sobre conflictos de intereses". Revista Arbitraje PUCP, número 50, pp. 234-239. Disponible en http://revistas.pucp.edu.pe/index.php/ iusetveritas/article/view/14817/15373
Fernández de Bujan, A. (2012) "Del Arbitraje romano configurado a semejanza de los juicios (compromisso quod iudicium imitatur)", Revista de Derecho UNED, número 11. España. Disponible en: http://espacio.uned.es/fez37/public/collection/ bibliuned:RDUNED-2012-11

Fernández Palacio, L. (2016) “Análisis del arbitraje y su idoneidad para la resolución de conflictos en el derecho español". Universidad Internacional de La Rioja, España. Tesis de titulación en Derecho. Disponible en: http://reunir.unir.net/bitstream/ handle/123456789/4417/FERNANDEZ\%20 PALACIO $\% 2 \mathrm{C} \% 20$ LAURA.pdf? sequence $=1$

Gonzáles de Cossío, Francisco "El arbitraje evaluado: Comentarios sobre experiencias recientes en México". Disponible en: http://www.gdca.com.mx/PDF/arbitraje/ ARBITRAJE\%20EVALUADO.pdf

Guzmán-Barrón Sobrevilla, César; Zúñiga Maravi, Rigoberto; Seminario Reyes, Carlos (2016) "Ética en el Arbitraje de Contratación Pública: Problemas y Soluciones". Revista Arbitraje PUCP, número 6, pp. 94116. Disponible en http://revistas.pucp. edu.pe/index.php/arbitrajepucp/article/ view/17029/17327 